\title{
Anti-explosion Capability and Impact Response of an Innovative Multi-layered Composite Explosion Containment Vessel
}

\section{Qi Yuan}

Army Engineering University of PLA

Heng Chen ( $\square$ hengchen.123@nuaa.edu.cn )

Army Engineering University of PLA

Wenbin Gu

Army Engineering University of PLA

\section{Zhen Wang}

Army Engineering University of PLA

\section{Likai Hao}

Army Engineering University of PLA

\section{Research Article}

Keywords: Composite explosion containment vessel, Overpressure, Three dimensional mesoscopic 30 model, Steel plate, Aluminum honeycomb, Fiber cloth

Posted Date: September 8th, 2021

DOl: https://doi.org/10.21203/rs.3.rs-837089/v1

License: (c) (1) This work is licensed under a Creative Commons Attribution 4.0 International License. Read Full License 


\section{Anti-explosion Capability and Impact Response of an Innovative Multi-layered}

\section{Composite Explosion Containment Vessel}

${ }^{\text {a }}$ State Key Laboratory of Disaster Prevention \& Mitigation of Explosion \& Impact, Army Engineering University of PLA,

${ }^{\mathrm{b}}$ School of Field Engineering, Army Engineering University of PLA, Jiangsu Nanjing 210007, China

${ }^{\mathrm{c}}$ Unit 66133 of PLA, Beijing 100000, China

*Corresponding author: Heng Chen: hengchen.123@nuaa.edu.cn Tel: +86 14751688128

\section{9} is examined through experimental tests and simulations, and a three-dimensional mesoscopic model is established and verified. Furthermore, to solve the problem of the restricted explosion resistance

19 of the single-layer ECV, a new steel plate-aluminum honeycomb-fiber cloth sandwich structure with

20 sliding lining is proposed to design a multi-layer CECV. For the arrangement of fiber filaments, 21 uniform distribution, random distribution, and honeycomb distribution algorithms are established 
23 of explosion simulations are conducted. The results indicate that the laying angle of the fibre cloth

24 has no effect on the peak overpressure inside the ECV, and the ECV exhibits the best protective property when the laying angle of the fibre cloth is $0 \% 45^{\circ} / 90^{\circ} / 45^{\circ} / 0^{\circ}$. It is also observed that the steel plate-aluminium honeycomb-fibre cloth sandwich structure prolongs the action time of the explosion shock wave and greatly reduces the peak pressure in the CECV. Remarkably, for the weakest position of the tank, the strain for the multi-layer CECV under $3000 \mathrm{~g}$ TNT is even less than that for the single-layer ECV under $150 \mathrm{~g}$ TNT.

Keywords: Composite explosion containment vessel; Overpressure; Three-dimensional mesoscopic model; Steel plate; Aluminum honeycomb; Fiber cloth

\section{Introduction}

The safe handling of discarded weapons and ammunition and reduce its destructive effect is a topic of current research [1]. Explosion containment vessels (ECVs) have been widely used in military, civil and industrial fields to limit the scope of internal explosion shock wave, protect personnel and equipment [2,3]. Notably, several drawbacks, such as bulkiness, single structure and limited blast-resistance performance against high charge explosives, gradually appear in commonly used single-layer ECVs. Therefore, some improved ECVs with new materials and structures have been designed to contain the impact of explosion. Particularly, composite ECVs (CECVs) has been widely used because of its high strength, low density and better performance than steel ECVs [4].

Over the recent years, the propagation and attenuation of shock waves in ECVs have been extensively examined through experiments. Ren et al. [5] studied the attenuation characteristics of 
43 stress wave in aluminum foam sandwich cylindrical explosion tank through experiments. It was

44 found that aluminum foam greatly reduced the strength of stress waves, and the "hard-soft-hard"

45 composite structure was proved to a reasonable explosion-proof structure. Wang [6] studied the load

46 distribution and dynamic response of a CECV with filament wound metal lining and found that the

47 beat phenomenon appeared on the cylinder of the vessel. Such a vessel is lightweight and has good

48 anti-explosion ability. Cui et al. [7] examined the dynamic response of a multi-layer ECV under the

49 action of internal explosion. It was suggested that the transmission of stress waves in the multi-layer

50 medium caused the outer wall to be first subjected to impact compression from the inside. Dong et

51 al. [8] experimentally analyzed the dynamic response of carbon fiber cylindrical shells. The results

52 indicated that the carbon fiber cylindrical shells demonstrated better explosion-resistant

53 performance than the glass fiber cylindrical shells for the specific types of tests and shell

54 configurations considered. Liu et al. [9] designed a single-layer cylindrical ECV and a new

55 multi-layer cylindrical ECV composed of single-layer ECV and aluminum foam sacrificial inner

56 lining, and the results showed that the energy-absorbing inner lining has a certain protective effect

57 on the CECV, shortens the vibration time of the CECV and changes the strain growth mechanism of

58 the vessel shell.

However, experimental investigations are usually difficult selection of the test site, high cost,

60 heavy workload, and time-consuming, and it cannot provide insights on the explosion-resistant

61 mechanism and dynamic response of ECV. Further, the existing theoretical studies on ECV mostly

62 focus on its elastic response. Baker [10] investigated the elastic-plastic response of a thin spherical

63 shell under spherically symmetric internal transient pressure loading. Analytic solutions are 
64 obtained to the linear, small-deflection equations of motion for shell materials which exhibit various

65 degrees of strain-hardening. Duffey and Mitcheli [11] presented an experimental and theoretical

66 investigation of the high explosive containment ability of ECV. Based on the rigid-plastic material

67 relation for the ECV, the functional expression of the final circumferential strain or radial

68 displacement and the length of the cylinder length is derived.

69 Zhu et al. [12] conducted the formation and development of dynamic strain growth and the

70 factors which affect it of ECV under internal blast loading, and theoretical treatment of the strain

71 growth and strain growth factor is given for the first time. It is pointed out that the superposition

72 and interaction of different modes of response with similar frequencies is regarded as the

73 mechanism of strain growth. Wang et al. [13] developed an elastodynamic method to determine the

74 dynamic stresses in a multi-layered ECV subjected to dynamic pressure, and the dynamic stresses in

75 a two-layer cylinder and a sandwich cylinder subjected to sudden interior pressure were calculated.

76 Zheng et al. [14] studied the dynamic elastic response of a discrete multi-layered cylindrical shell

77 (DMC) under uniformly distributed pressure pulse, and the effects of parameters, such as thickness

78 ratio of the inner shell to that of the complete shell, material parameters, and winding-angle, were

79 discussed. Chen et al. [15] established a cylindrical ECV model and the dynamic burst pressure

80 equation of the ECV under the explosive load was obtained, finally the accuracy of this equation

81 was verified by comparison with the results of finite element (FE) method.

In general, the mesoscopic model can effectively reveal the mechanism by which the ECV

83 contains the internal explosion shock wave, and the protective structure of each layer of the ECV

84 can be modeled separately from the air, so that the gas-solid interaction can be easily captured, and 

the protective effect of each layer of the multi-layer ECV can be analyzed separately. Karpp et al. [16] investigated the response of steel containment vessels to the blast loading by both finite-difference (FD) and FE computer codes. The two-dimensional motion, which occurred after significant wave interactions had taken place in the test vessels, was simulated by FE method. Dong et al. summarized the previous studies [17-19] and systematically analyzed the strain growth mechanism of cylindrical shells to propose a design method for ECVs based on an equivalent single-degree-of-freedom (SDOF) design method and three-dimensional (3D) FE analysis [20]. Due to the complexity of the explosion process and relevant structure, the propagation process and influence law of the shock wave in the sandwich layer of the ECV as well as the influence of the structural parameters of the ECV on the reflection overpressure on the inner wall have not been clarified yet. Furthermore, in the earlier studies, the explosion load was usually simplified to a uniform pressure, which is an impractical assumption. Therefore, in this paper, a 3D mesoscopic model of single-layer ECV is established, and its explosion-resistant performance is examined both experimentally and numerically. Then, a new type of multi-layer CECV is established, and it is proved that the multi-layer $\mathrm{CECV}$ is superior to the single-layer ECV in terms of both anti-explosion ability and energy absorption effect. Furthermore, the effects of lining form and material on the anti-explosion ability are analyzed. The failure and deformation of the sandwich layer and the dynamic response of the shell are also investigated.

\section{Experiments setup}

Four tests with different charge weight (27 g, $64 \mathrm{~g}, 120 \mathrm{~g}$ and $150 \mathrm{~g}$ ) were conducted, TNT explosive charges were used to generate the shock wave, and the experimental data such as internal 
106 pressure and strain of the single-layer ECV are recorded and discussed in detail.

\subsection{Single-layer cylindrical explosion container vessels}

The internal explosion experiment was performed in the single-layer ECV designed by our

109 group [9], whose dimensions are listed in Table 1. The single-layer ECV shell, bottom head, flange

110 and head cover, as shown in Fig. 1. The bottom head was welded on the shell, and the head cover

111 was coupled with the shell by bolts. The upper end cap was tightly connected to the container body

112 through a flange and bolt structure. The ellipsoidal end cap was connected to a cylindrical flange.

113 Eight test holes were reserved on symmetrical sides of the cylinder, and a pressure relief valve was

114 installed on the pressure relief pipe. The inner diameter and the thickness of the shell are $150 \mathrm{~mm}$

115 and $18.5 \mathrm{~mm}$, respectively.

116

Table 1. Dimensions of the ECV

\begin{tabular}{cccccc}
\hline $\begin{array}{c}\text { Inner } \\
\text { diameter }\end{array}$ & $\begin{array}{c}\text { Cylinder } \\
\text { height }\end{array}$ & $\begin{array}{c}\text { Length/diameter } \\
\text { ratio }\end{array}$ & Thickness & $\begin{array}{c}\text { Dynamic load } \\
\text { coefficient }\end{array}$ & $\begin{array}{c}\text { Equivalent } \\
\text { static load }\end{array}$ \\
\hline $800 \mathrm{~mm}$ & $1170 \mathrm{~mm}$ & $2: 1$ & $22 \mathrm{~mm}$ & 0.56 & $6.79 \mathrm{MPa}$ \\
\hline
\end{tabular}

$117 \quad 2.2$ Experiment vessels and test system

118 In the experiment, a total of five measurement points (P1-P5) were set on the side wall of the

119 cylinder to test the reflection overpressure and strain of the wall surface. The locations of these

120 points are shown in Fig. 1 . The points P2, P3, and P4 are 150, 300, and $450 \mathrm{~mm}$ away from P1, and

121 P5 is located at the pole point of the oval-shaped lower end cap. 

reflection overpressure at the P4 measuring point at the same time. The P5 measurement point is

134 located at the bottom of the end cap. The peak value of overpressure increases significantly after

135 superposition, and the superposition effect is obvious. Table 2 shows the peak pressure of each

\subsection{Experiments on Shell Response}

Fig. 2 compares the typical pressure-time curves of the measurement points when $120 \mathrm{~g}$ charge explodes at different positions in the container. The pressure-time curve is consistent with the basic waveform of the explosion shock wave reflection, i.e., there is a very steep rising edge. After the shock wave pressure reaches its peak, it decreases almost exponentially, and multiple superimposed waveforms are generated. For different locations under the same charge, the reflection overpressure and the specific impulse at the P1-P4 position gradually decreases with the increase in the distance from the explosion center, and the time to reach each measuring point is obviously prolonged. There is obvious reflection overpressure at the points $\mathrm{P} 1, \mathrm{P} 2$ and $\mathrm{P} 3$ in a short time, and there is no measurement point under different charges. The empirical value is obtained by the simulation

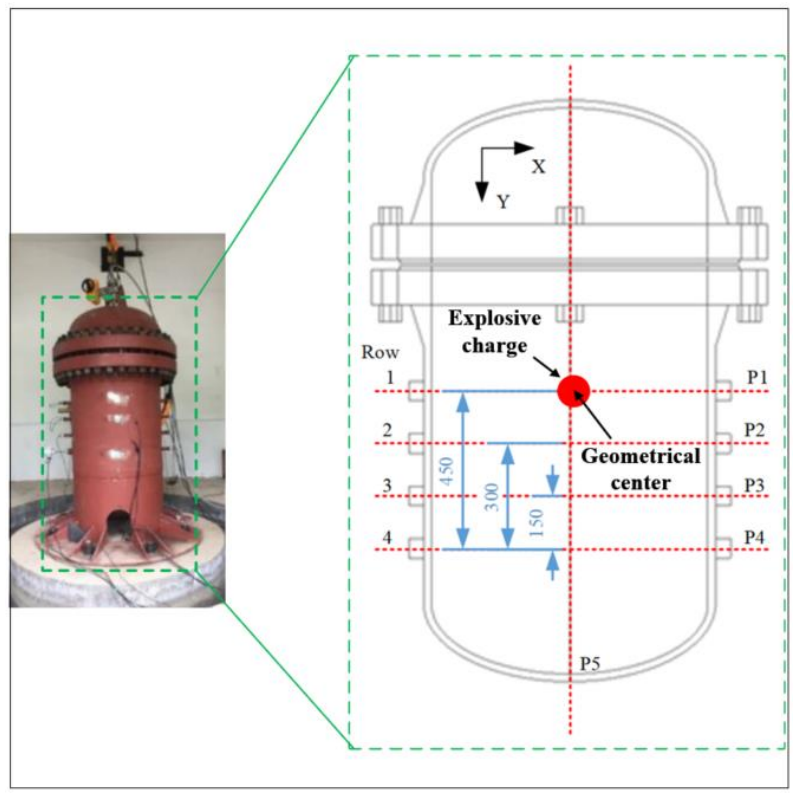

Fig. 1 Layout of the measurement points (left) and a snapshot of the ECV (right) 
137 equation of explosion load in an enclosed ECV, as proposed by Deng et al. [21] and Lin et al. [22].

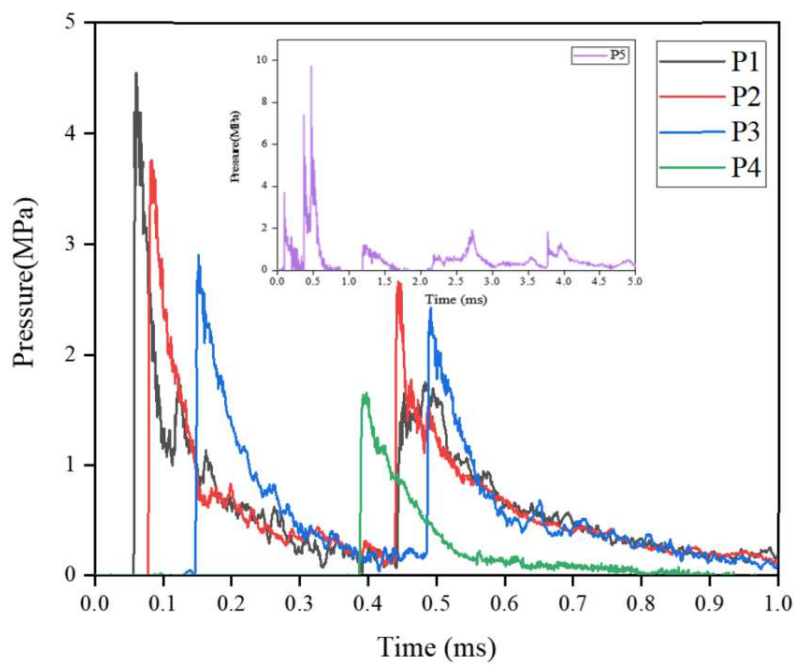

139 Fig. 2 Peak overpressure-time curves for each measurement point under the action of $120 \mathrm{~g}$ TNT equivalent

141 Table 2. Experimental and simulated values of the peak overpressure at each measurement point

\begin{tabular}{|c|c|c|c|c|c|c|c|}
\hline \multirow{3}{*}{ No. } & \multirow{3}{*}{$\begin{array}{l}\text { Charge } \\
\text { quantity } \\
\text { (g) }\end{array}$} & \multicolumn{6}{|c|}{ Peak pressure (MPa) } \\
\hline & & \multicolumn{3}{|c|}{$\mathrm{P} 1$} & \multicolumn{3}{|c|}{$\mathrm{P} 2$} \\
\hline & & $\begin{array}{c}\text { Experimental } \\
\text { value }\end{array}$ & $\begin{array}{c}\text { Empirical } \\
\text { value }\end{array}$ & Error & $\begin{array}{c}\text { Experimental } \\
\text { value }\end{array}$ & $\begin{array}{c}\text { Empirical } \\
\text { value }\end{array}$ & Error \\
\hline 1 & 27 & 1.69 & 1.78 & 0.05 & 1.56 & 1.8 & 0.13 \\
\hline 2 & 64 & 2.52 & 2.53 & 0.00 & 2.63 & 2.26 & 0.16 \\
\hline 3 & 120 & 4.54 & 3.88 & 0.17 & 3.81 & 3.48 & 0.09 \\
\hline 4 & 150 & 6.75 & 5.4 & 0.25 & 5.27 & 4.83 & 0.09 \\
\hline \multirow{3}{*}{ No. } & \multirow{3}{*}{$\begin{array}{l}\text { Charge } \\
\text { quantity } \\
\text { (g) }\end{array}$} & \multicolumn{6}{|c|}{ Peak pressure $(\mathrm{MPa})$} \\
\hline & & \multicolumn{3}{|c|}{ P3 } & \multicolumn{3}{|c|}{$\mathrm{P} 4$} \\
\hline & & $\begin{array}{c}\text { Experimental } \\
\text { value }\end{array}$ & $\begin{array}{c}\text { Empirical } \\
\text { value }\end{array}$ & Error & $\begin{array}{c}\text { Experimental } \\
\text { value }\end{array}$ & $\begin{array}{c}\text { Empirical } \\
\text { value }\end{array}$ & Error \\
\hline 1 & 27 & 0.98 & 1.18 & 0.17 & 0.59 & 0.73 & 0.19 \\
\hline 2 & 64 & 1.7 & 1.69 & 0.01 & 1.13 & 1.57 & 0.22 \\
\hline 3 & 120 & 2.9 & 2.6 & 0.12 & 1.6 & 1.17 & 0.37 \\
\hline 4 & 150 & 4.39 & 3.62 & 0.21 & 2.7 & 2.5 & 0.08 \\
\hline No. & Charge & \multicolumn{6}{|c|}{ Peak pressure $(\mathrm{MPa})$} \\
\hline
\end{tabular}




\begin{tabular}{ccccc}
\hline & quantity & \multicolumn{3}{c}{ P5 } \\
\cline { 3 - 5 } & $(\mathrm{g})$ & Experimental & Empirical \\
& & value & value & Error \\
\hline 1 & 27 & 4.52 & 0.57 & 6.90 \\
2 & 64 & 9.18 & 0.73 & 18.59 \\
3 & 120 & 9.74 & 1.88 & 4.19 \\
4 & 150 & 13.6 & 1.55 & 7.9 \\
\hline
\end{tabular}

It is clear that there is a large deviation between the experimental and calculated values for the

143 measurement at point P5, indicating that the Lin's equation [22] is not suitable for the simulation of

144 peak overpressure at the end cap pole points of an ellipsoid. For the measurement at points P1, P2,

145 P3 and P4 on the cylindrical shell, the errors between the experimental and calculated values are

146 within $0-37 \%$, and only two measurement points have errors of more than $20 \%$. This suggests that

147 there is some deviation between the experimental and empirically calculated values. Therefore, to

148 improve the simulation accuracy of the peak overpressure under an internal explosion load, Lin's

149 equation is modified based on the peak overpressure of measurement at points P1, P2, P3 and P4.

150 The peak overpressure and the proportional explosion distance of the measurement at the

151 P1-P4 position in Table 2 are fitted using MATLAB, and the corresponding results are shown in Fig.

152 3. The regression equation is as follows:

153

$$
f(x)=a * \exp (-b * x)
$$




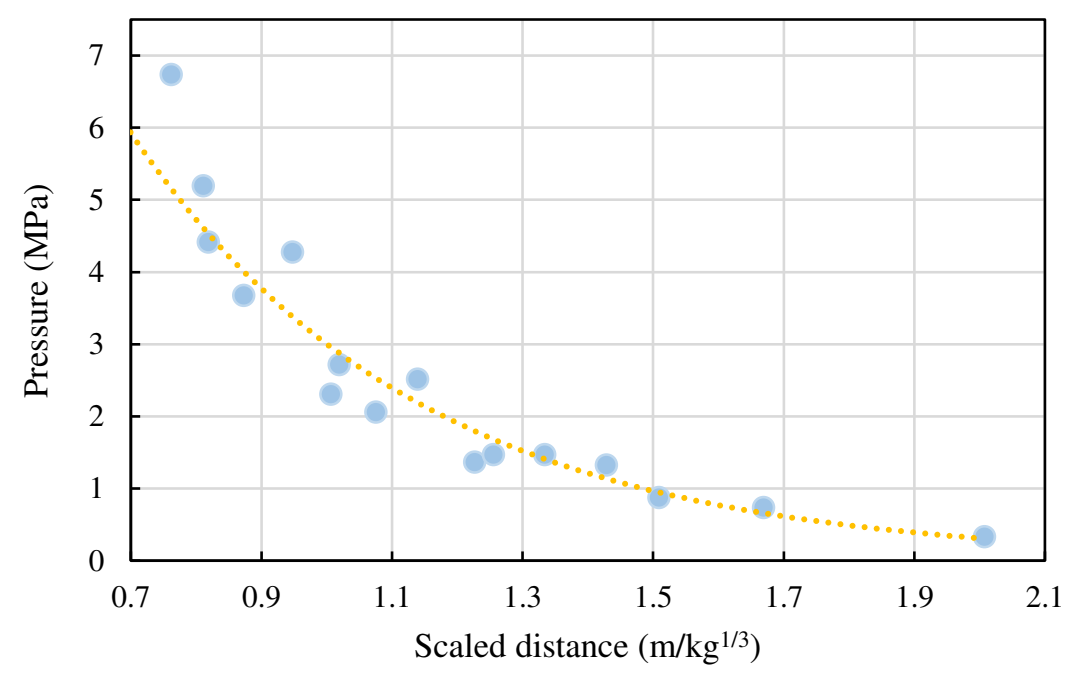

154

Fig. 3 Fitting curves of the peak overpressure and proportional explosion distance at each measurement point under different charge quantities

In the regression model, the correlation coefficient is 0.98 in the $95 \%$ confidence interval, and

158 the specific values of constants are determined as $a=28.99, \mathrm{~b}=2.267$, respectively. The

159 determination coefficient $R^{2}$ is 0.9561 . Because the determination coefficient is close to 1 , it can be

160 inferred that the regression equation is reasonable with high fitting accuracy. Therefore, the revised

161 equation of the peak reflection overpressure of shock wave is expressed as,

$$
f(x)=28.99 \times \exp (-2.267 \times R / \sqrt[3]{W})
$$

163 where $R$ denotes the linear distance between the explosive and the measurement point on the shell,

164 and $W$ denotes the mass of the explosive. It can be seen from the figure that the peak overpressures

165 of the measurement at the P1-P4 position under the different charge quantities decrease with the

166 increase in the distance from the explosion center. 

deformation under the action of explosion load, the Johnson-Cook (JC) material model is used to

mesoscopic FE model of single-layer ECV is established based on the dimensions of the explosion test system in which the influence of actual explosives is considered. The anti-explosion ability and energy absorption effect of ECV are numerically simulated using LS-DYNA.

\subsection{Model parameters of the materials}

The 3D mesoscopic FE model of the field test model is composed of TNT explosive, air, and ECV, and a fluid-solid coupling algorithm is used, as shown in Fig. 4. The shell is modeled by Lagrange sub-grid with a hexahedral mesh size of $5.5 \times 5.5 \times 5.5 \mathrm{~mm}^{3}$, the number of elements is 281823. However, the air and TNT charge are modeled by Euler sub-grid with a hexahedral mesh size of $10 \times 10 \times 10 \mathrm{~mm}^{3}$, and the number of elements is 1583282 . The Eulerian (fluid) domain grid is slightly larger than the Lagrangian (solid) domain grid to ensure the effective fluid-solid interaction considered in the coupling algorithm available in LS-DYNA. The charge weight of the explosive are $27 \mathrm{~g}, 64 \mathrm{~g}, 120 \mathrm{~g}$, and $150 \mathrm{~g}$, respectively.

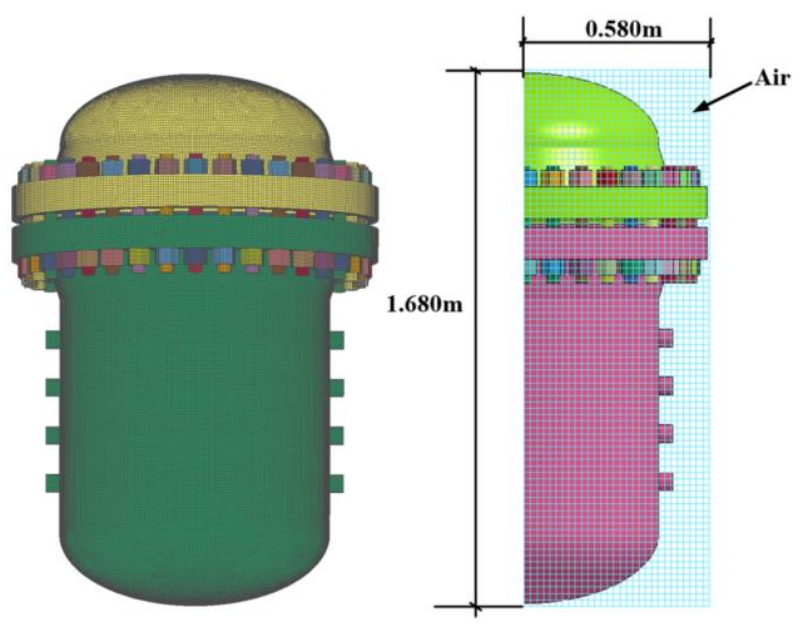

Fig. 4 3D model of ECV

To accurately describe the mechanical properties of the ECV in the explosion, especially the simulate the mechanical behavior of the ECV. The vessel body is made of Q345 steel. The 

parameters of JC material model are shown in Table 3.

Table 3. Simulation parameters of the JC material model for the vessel body

\begin{tabular}{ccccccccc}
\hline$D_{1}$ & $D_{2}$ & $D_{3}$ & $D_{4}$ & $D_{5}$ & $G(\mathrm{GPa})$ & $C$ & $S_{1}$ & $\gamma_{0}$ \\
\hline 0.05 & 3.44 & -2.12 & 0.002 & 1.61 & 82.82 & 0.4569 & 1.49 & 2.17 \\
\hline$n$ & $C_{p}(\mathrm{~J} / \mathrm{kg} \cdot \mathrm{K})$ & $m$ & $T_{\mathrm{r}}$ & $\mu$ & $A$ & $B$ & $\rho\left(\mathrm{kg} / \mathrm{m}^{3}\right)$ & \\
\hline 0.18 & 460 & 1.0 & 293 & 0.3 & 345 & 477 & 7870 & \\
\hline
\end{tabular}

Table 4. Parameters of the JWL equation of state

\begin{tabular}{cccccccccc}
\hline$\rho\left(\mathrm{kg} / \mathrm{m}^{3}\right)$ & $A(\mathrm{GPa})$ & $B(\mathrm{GPa})$ & $R_{1}$ & $R_{2}$ & $P C J(\mathrm{GPa})$ & $E\left(\mathrm{~J} / \mathrm{m}^{3}\right)$ & $D(\mathrm{~m} / \mathrm{s})$ & $v$ & $\omega$ \\
\hline 1500 & 347.6 & 3.39 & 4.15 & 0.95 & 17.92 & $6.34 \times 10^{9}$ & 6957.2 & 1.0 & 0.28 \\
\hline
\end{tabular}

An arbitrary Lagrangian-Eulerian (ALE) grid is used for air modeling. The parameters of the

193 air model are shown in Table 5.

Table 5. Simulation parameters of the air [24]

\begin{tabular}{cccccccc}
\hline$C_{0}(\mathrm{MPa})$ & $C_{1}$ & $C_{2}$ & $C_{3}$ & $C_{4}$ & $C_{5}$ & $C_{6}$ & $\rho\left(\mathrm{kg} / \mathrm{m}^{3}\right)$ \\
\hline-0.1 & 0 & 0 & 0 & 0.4 & 0.4 & 0 & 1.225 \\
\hline
\end{tabular}

196 simulation accuracy and efficiency, a simplified JC model is used for the nuts and bolts. The

197 simulation parameters of this model are shown in Table 6.

Table 6. Simulation parameters of the JC material model for the nuts and bolts

\begin{tabular}{cccccccccc}
\hline Parameter & $E(\mathrm{GPa})$ & $C$ & $\mu$ & $A$ & $n$ & $B$ & $m$ & $\rho\left(\mathrm{kg} / \mathrm{m}^{3}\right)$ & $T_{\mathrm{r}}$ \\
\hline Value & 82.82 & 0.014 & 0.2804223 & 835 & 0.26 & 510 & 1.0 & 7850 & 293 \\
\hline
\end{tabular}




\subsection{Numerical results and discussion}

The simulation results of the typical pressure at each measurement point when 27, 64, 120, and

$201150 \mathrm{~g}$ charges are exploded at different positions within the single ECV are shown in Fig. 5. The peak reflection overpressure at each measurement point on the explosion center torus increases with the increase in the charge quantity. It is observed that the peak reflection overpressure of $64 \mathrm{~g}$ TNT equivalent explosion shock wave at points P1-P4 increases by 2.08-2.56 times. When the explosive mass is $120 \mathrm{~g}$, the peak reflection overpressure at P1-P4 is 1.83-3.71 times higher than that when the explosive mass is $27 \mathrm{~g}$. At $150 \mathrm{~g}$ TNT equivalent, the peak reflection overpressure at P1-P4 is 3.07-5.35 times higher than that at $27 \mathrm{~g}$. For different charge quantities at the same position, the reflection overpressure and the specific impulse gradually increase with the increase in the charge quantity, which is consistent with the results of Langdon et al. [25, 26] and Jacob et al. [27]. For different positions with the same charge quantity, the reflection overpressure, and the specific

211 impulse at P1-P4 decrease with the increase in the distance from the explosion center.

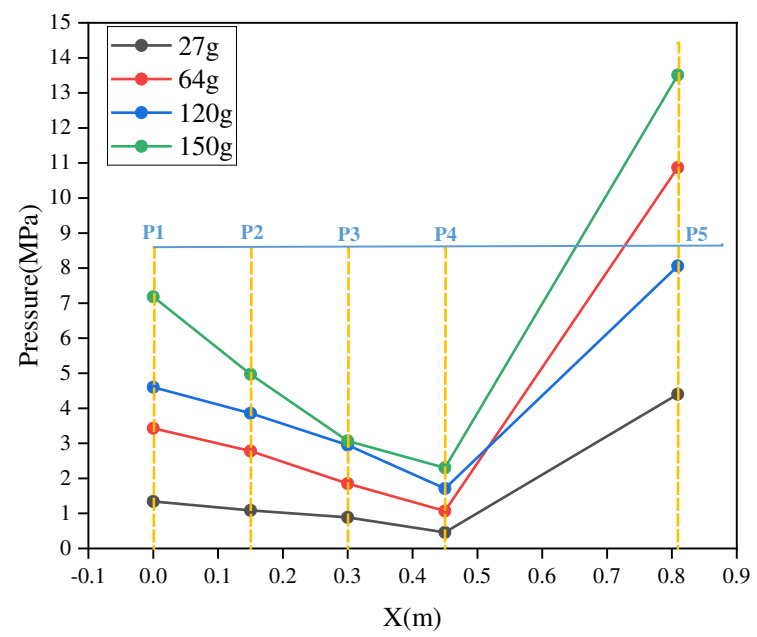

213 Fig. 5 Numerical simulation results of the peak overpressure at each measurement point under different charge quantities. 

pressure imposed by explosion shock waves using 27, 64, 120, and $150 \mathrm{~g}$ charges at the measurement points P1-P4. To quantitatively describe the difference between the experimental and simulation results, the numerically simulated peak pressure imposed by the explosion shock waves is taken as the $\mathrm{X}$-axis and the experimental results are taken as the Y-axis in Fig. 6a. Here, the straight line with a slope of 1 indicates that the simulation results are identical to the experimental results. When the test point is below (above) this straight line, it indicates that the numerical value is higher (lower) than the experimental value. It is clear from Fig. 6a that the test points fall between the solid line with a slope of 1 and the dashed line with a slope of 0.8 , indicating that the error is generally within $20 \%$.

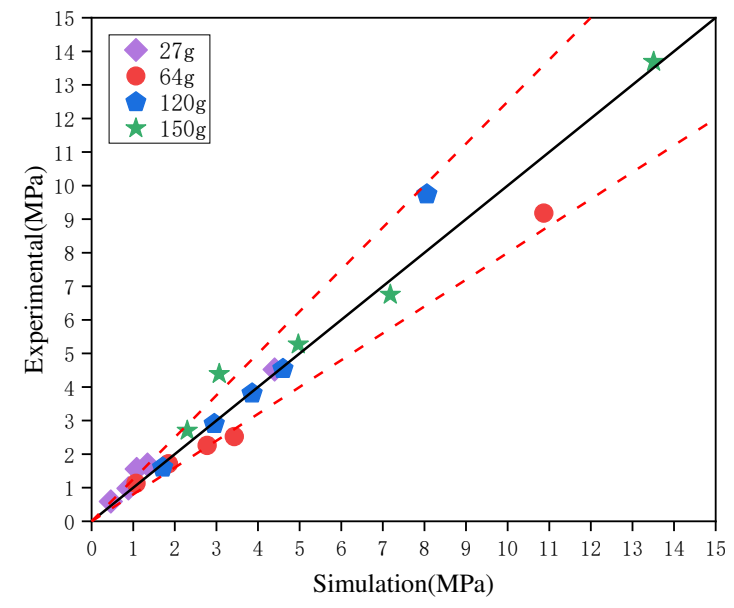

(a)

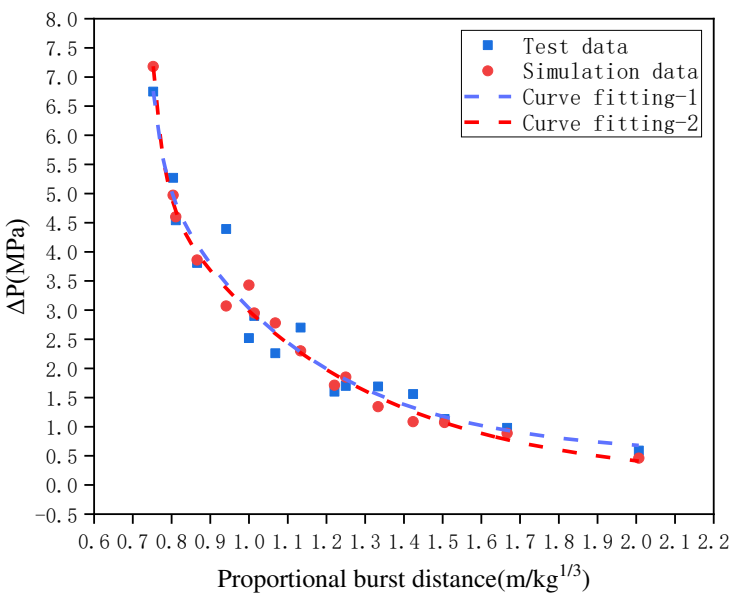

(b)

225 Fig. 6 Comparison between the numerical and experimental results of the peak overpressure. (a)

226 Comparison between the experimental and simulated values; (b) fitting curve of the experimental and simulated values.

As shown in Fig. 6b, the numerical simulation results under different charge quantities are in good agreement with the experimental results. The peak reflection overpressure of the measurement points P1-P4 gradually decrease with the increase in the proportional explosion distance. The fitting 
231 curves of the experimental and simulation results are approximately coincident, indicating a good

232 simulation accuracy. It can be noted from Fig. 6b that the experimental values are slightly higher

233 than the simulated values.

234 A comparison between the results based on the experiment and improved Lin's equation is

235 presented in Table 7. It is evident that the error between the experimental value at P1-P2 and the

236 calculated value using improved Lin's equation is within $0-14 \%$, which indicates the improvement

237 in the simulation accuracy of the peak overpressure of the explosion load in the enclosed ECV.

Table 7. Simulation results of the peak overpressure at each measurement point.

\begin{tabular}{|c|c|c|c|c|c|c|c|}
\hline \multirow{3}{*}{ No. } & \multirow{3}{*}{$\begin{array}{c}\text { Charge } \\
\text { quantity (g) }\end{array}$} & \multicolumn{6}{|c|}{ Peak pressure (MPa) } \\
\hline & & \multicolumn{3}{|c|}{$\mathrm{P} 1$} & \multicolumn{3}{|c|}{$\mathrm{P} 2$} \\
\hline & & $\begin{array}{c}\text { Experimental } \\
\text { value }\end{array}$ & $\begin{array}{c}\text { Empirical } \\
\text { value }\end{array}$ & Error & $\begin{array}{c}\text { Experimental } \\
\text { value }\end{array}$ & $\begin{array}{c}\text { Empirical } \\
\text { value }\end{array}$ & Error \\
\hline 1 & 27 & 1.69 & 1.53 & 0.10 & 1.56 & 1.45 & 0.07 \\
\hline 2 & 64 & 2.52 & 2.65 & -0.05 & 2.63 & 2.35 & -0.04 \\
\hline 3 & 120 & 4.54 & 4.99 & -0.10 & 3.81 & 4.34 & -0.14 \\
\hline 4 & 150 & 6.75 & 6.69 & 0.01 & 5.27 & 5.68 & -0.08 \\
\hline \multirow{3}{*}{ No. } & \multirow{3}{*}{$\begin{array}{c}\text { Charge } \\
\text { quantity (g) }\end{array}$} & \multicolumn{6}{|c|}{ Peak pressure $(\mathrm{MPa})$} \\
\hline & & \multicolumn{3}{|c|}{$\mathrm{P} 3$} & \multicolumn{3}{|c|}{ P4 } \\
\hline & & $\begin{array}{c}\text { Experimental } \\
\text { value }\end{array}$ & $\begin{array}{c}\text { Empirical } \\
\text { value }\end{array}$ & Error & $\begin{array}{c}\text { Experimental } \\
\text { value }\end{array}$ & $\begin{array}{c}\text { Empirical } \\
\text { value }\end{array}$ & Error \\
\hline 1 & 27 & 0.98 & 1.04 & -0.06 & 0.59 & 0.58 & 0.02 \\
\hline 2 & 64 & 1.7 & 1.77 & -0.04 & 1.13 & 1.20 & -0.06 \\
\hline 3 & 120 & 2.9 & 3.06 & -0.06 & 1.6 & 1.56 & 0.02 \\
\hline 4 & 150 & 4.39 & 4.06 & 0.08 & 2.7 & 2.58 & 0.04 \\
\hline No. & Charge & \multicolumn{6}{|c|}{ Peak Pressure (MPa) } \\
\hline
\end{tabular}




\begin{tabular}{lcccc}
\hline & quantity $(\mathrm{g})$ & \multicolumn{3}{c}{ P5 } \\
\cline { 3 - 5 } & & $\begin{array}{c}\text { Experimental } \\
\text { value }\end{array}$ & $\begin{array}{c}\text { Empirical } \\
\text { value }\end{array}$ & Error \\
\hline 1 & 27 & 4.52 & 0.90 & 0.80 \\
2 & 64 & 9.18 & 1.20 & 0.87 \\
3 & 120 & 9.74 & 1.88 & 0.81 \\
4 & 150 & 13.6 & 2.28 & 0.83 \\
\hline
\end{tabular}

\subsection{Shock wave propagation}

Fig. 7 shows the change of air pressure in the internal with time ( 0 to $10 \mathrm{~ms})$ in the ECV under

242 the TNT charge weight of $150 \mathrm{~g}$. For each measurement point, the time at which the first pulse

243 reaches the measurement point $\mathrm{Pl}$ after the charge explodes at the center of the vessel is taken as the

244 reference time. In the model experiment, the initiation and the propagation process of the explosion

245 wave is clearly seen. The numerically simulated pressure-time curve is consistent with the basic

246 waveform of the explosion shock wave reflection, i.e., there is a very steep rising edge. After the

247 shock wave pressure reaches its peak, it decreases almost exponentially, as shown in Fig. 7b. At 0

$248 \mathrm{~ms}$, the charge explodes. The shock wave reaches the vessel wall around $0.16 \mathrm{~ms}$. The shock waves

249 are reflected due to the barrier of the vessel wall, and they move along the inner wall of the vessel

250 to the end. At $0.34 \mathrm{~ms}$, the intersection of the Mach reflection and the three waves is evident. At

$2510.58 \mathrm{~ms}$, the first shock wave that is generated by the shock wave converging at the vessel center

252 reaches the end cap. The first pressure peak appears at the pole point, and the shock wave

253 propagates faster in the denser air medium. However, due to the barrier of the vessel wall, the

254 convergence wave reaches the end cap pole point at $0.66 \mathrm{~ms}$ and forms the second peak before the 
255 Mach wave. At $0.7 \mathrm{~ms}$, the Mach reflection wave converges at the end cap pole point, forming the 256 third peak, as shown in Fig. 7a.

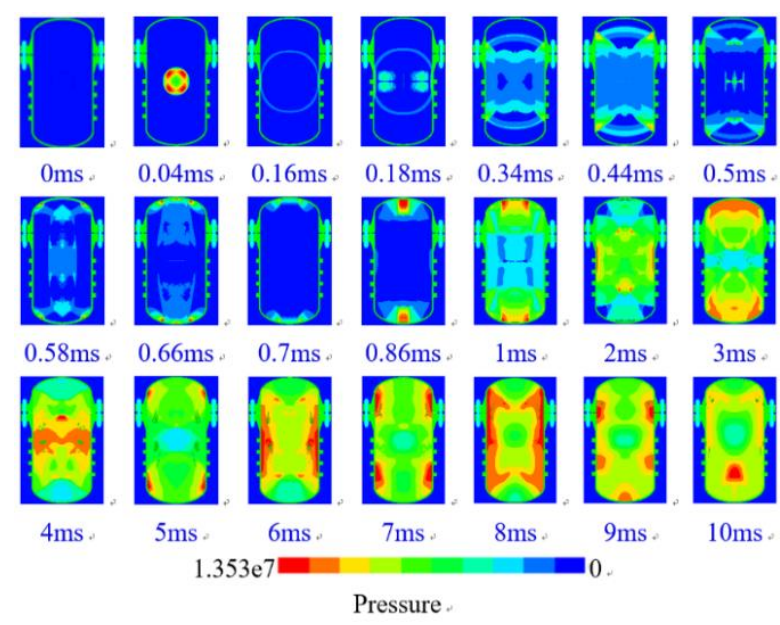

(a)

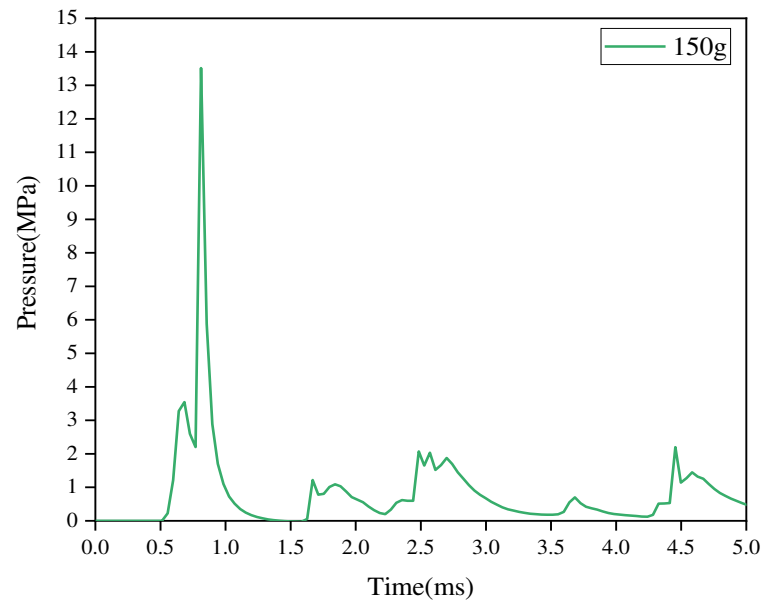

(b)

Fig. 7 ECV pressure analysis. (a) ECV pressure contour; (b) peak overpressure-time curve at the

\subsection{Specific impulse comparison}

The experimental groups with $27 \mathrm{~g}$ and $150 \mathrm{~g}$ TNT equivalents were selected, and the specific impulse was obtained by integrating the pressure during the action time of positive pressure. A comparison between the numerically simulated and experimentally obtained values of specific impulse is shown in Fig. 8. Here, the simulation and experimental results are taken as the $\mathrm{X}$-axis and $\mathrm{Y}$-axis, respectively. The straight line with a slope of 1 indicates that the simulation results are exactly identical to the experimental results. When the test point is below (below) the straight line, it indicates that the simulated value is higher (lower) than the experimental value. It can be seen from the figure that the test points mostly fall between the solid line with a slope of 1 and the dashed line with a slope of 0.8 , demonstrating that the experimental value of the specific impulse is smaller, and the error is generally within $20 \%$. There were two main reasons for this error. Firstly, in 
270 the experimental test, the explosion process has a certain discreteness. Therefore, small differences

271 exist in the results of multiple tests even if the mass and density of the charge are the same.

272 Secondly, in the numerical simulation, the ideal gas state equation is used to describe the high 273 temperature and high-pressure air, which induces errors. Furthermore, the presence of the grid 274 causes truncation and discretization errors.

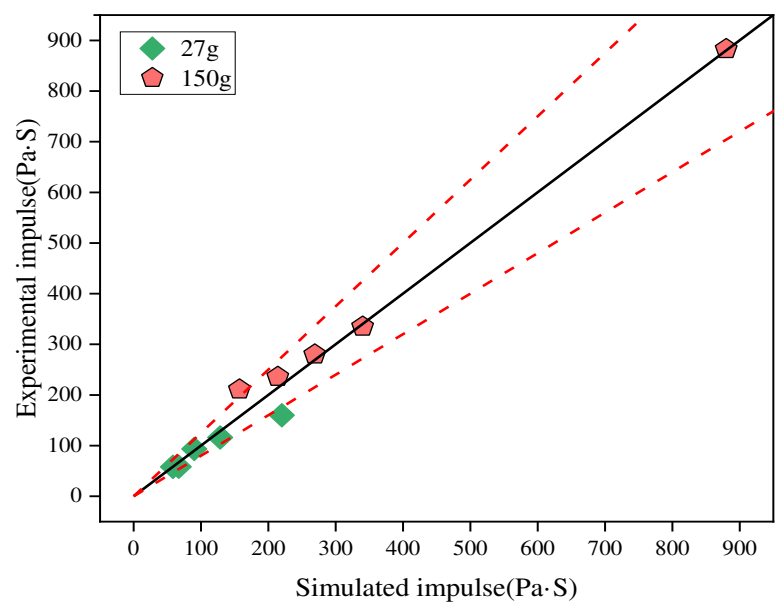

Fig. 8 Comparison between the experimental and numerically simulated specific impulse. duration and strong destructive force [28], and the damage effect mainly depends on the peak overpressure and positive pressure action time. For the CECVs, several possible criteria can be used to evaluate its explosion resistance, one criterion is the deflection of outer face sheet (DF). The DF under the internal explosion should be reduced to ensure the safety of the CECVs. Second, the attenuation effect of the protective material under the shock wave can be evaluated according to the pressure reaching the vessel.

Based on the experimental and simulation results of single-layer tank, it is concluded that the weakest position of the ECV is the end cover, so a sliding steel plate-aluminum honeycomb-fiber 
cloth structure is used to design the composite multi-layer explosion canister and increase the thickness of the aluminum honeycomb core at the weakest end cover. Under the explosion load, the sliding lining can compress the protective layer to the maximum extent, so that it can fully absorb the energy released by the explosion and reduce the explosion load directly acting on the outer wall of the explosion tank. The new multilayer CECV has an excellent application prospect in improving the anti-explosion ability [29-31]. In this section, the 3D model of aluminum honeycomb core and fiber cloth is established. The 3D solid meso-model at 1:1 is established by LS-DYNA software, and the explosion resistance of the new CECV is examined by numerical simulation.

\subsection{Finite element model}

The algorithm for the generation of aluminum honeycomb core consists of three steps. Firstly, the honeycomb geometry is generated through an array (as shown in Fig. 9). Secondly, the structural FE model is established to set the cell wall thickness for the extracted honeycomb geometry. Finally, the mesh mapping is carried out in the structural FE model, the coarse aggregate is deleted, the aluminum honeycomb core mesh is extracted, and the 3D FE model of aluminum honeycomb core is obtained. The 3D model of ECV lining and end cover lining is shown in Fig.10.

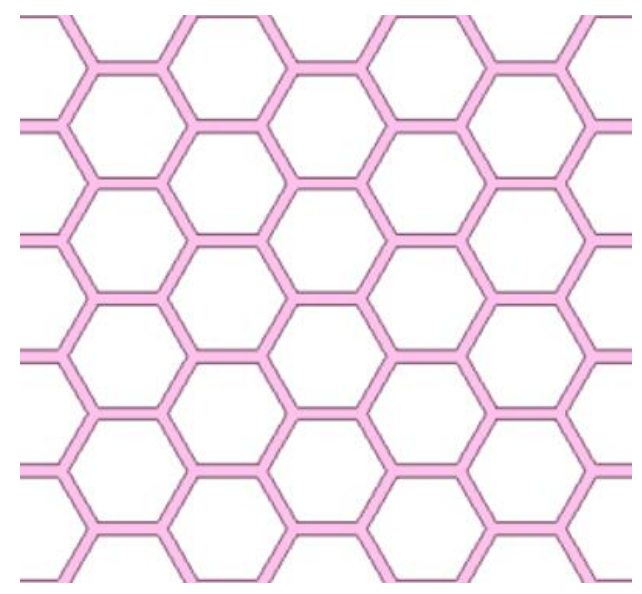

Fig. 9 Honeycomb model. 


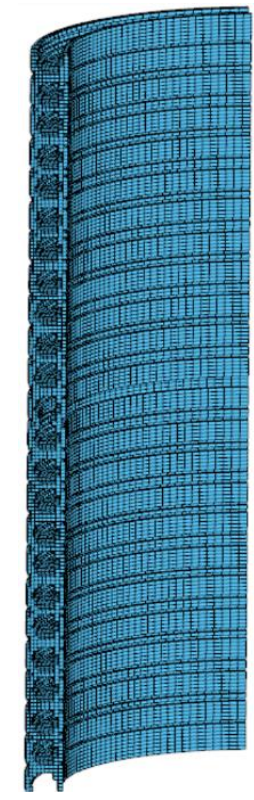

(a) Explosion containment tank lining

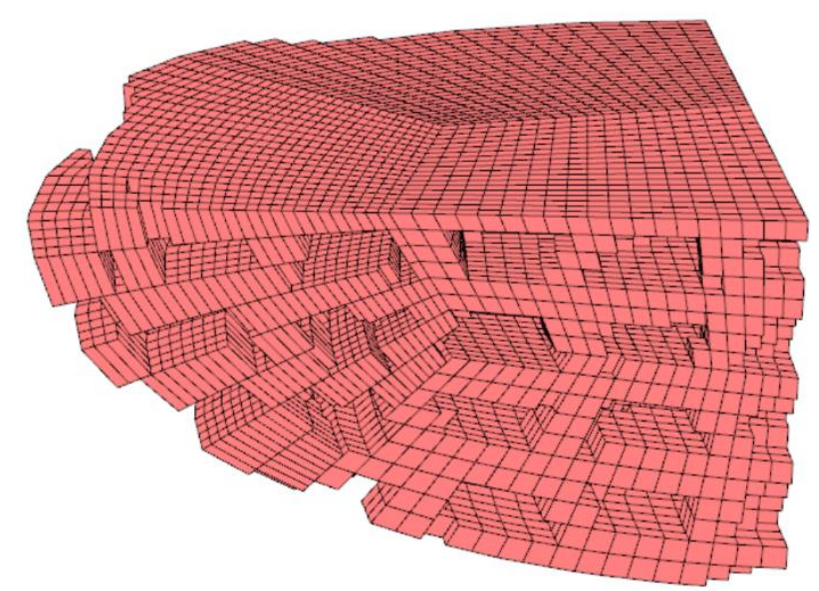

(b) End cover lining

Fig. 10 3D honeycomb model.

The generation algorithm of the carbon fiber cloth consists of four steps. In the first step, the representative volume unit of the unidirectional (UD) mesoscopic model of carbon fiber epoxy resin

307 and glass fiber-reinforced plastic (FRP) epoxy resin is analyzed. A Python program is used to 308 generate the UD microscopic model of fiber, as shown in Fig. 11(b), where the fiber content is $50 \%$ 309 and the fiber radius is $3 \mu \mathrm{m}$. The fiber filament and epoxy resin are connected by a common node, 310 and the epoxy resin is used as the matrix, which ensures the continuous deformation at the interface

311 between the fiber and epoxy resin and the complete transmission of node and unit information, as

312 shown in Fig. 11(c).
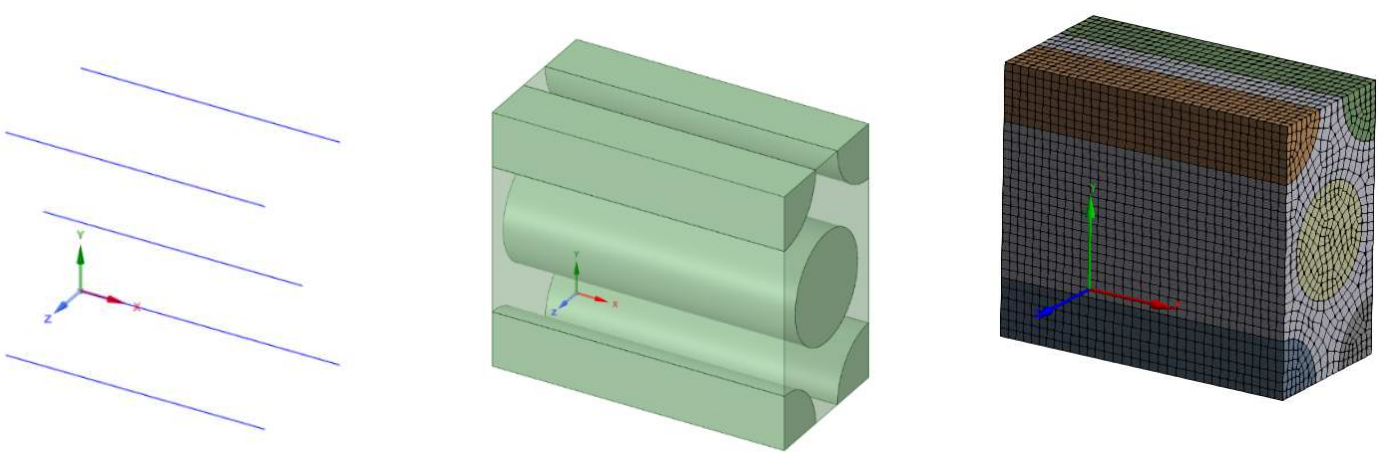

(a) Carbon fiber filament
(b) UD geometric model
(c) Finite element model

Fig. 11 UD microscopic model of fiber.

The parameters of the composite materials are calculated by the quasi-static stretching method, as shown in Fig. 12. One end of the fiber is stretched with a fixed constraint, and the other end is stretched with a constant displacement. The average tensile speed is $2 \mathrm{~mm} / \mathrm{min}$, and the other

317 directions are set by periodic boundary, as shown in Fig. 12.

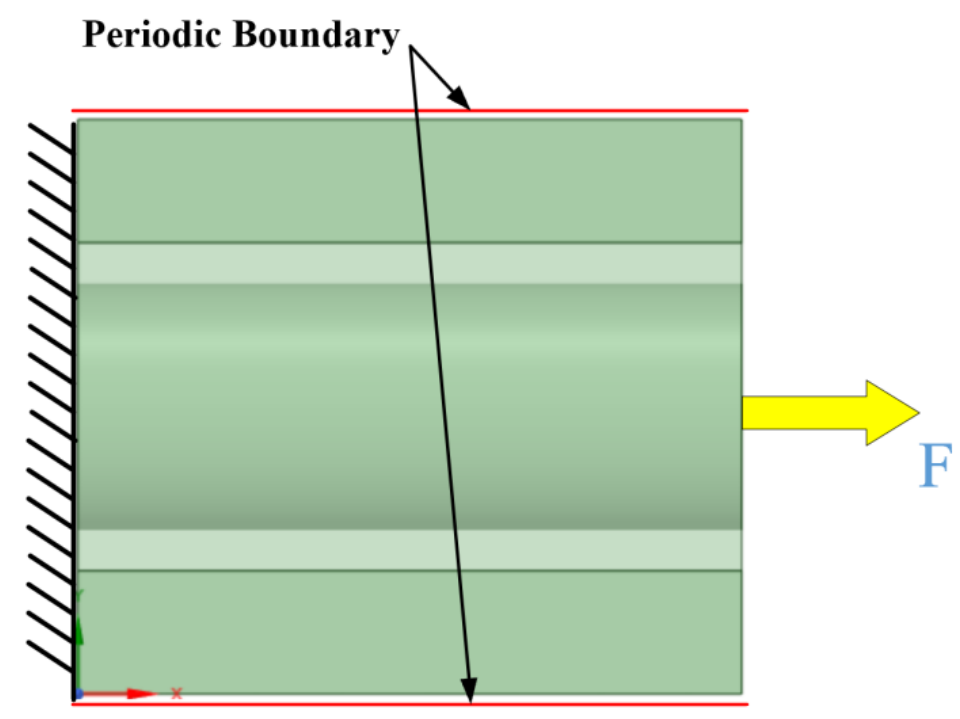

Fig. 12 Quasi-static stretching diagram.

To explore the influence of the arrangement of fiber filaments on the properties of fiber cloth, a

321 microscopic model of fiber cloth with different fiber filling coefficients is established, as shown in

322 Fig. 13. The fiber filaments are arranged in the following ways: honeycomb arrangement, uniform 323 arrangement, and random arrangement. The filament diameter of each arrangement is $50 \mu \mathrm{m}$. It is 324 clear from the figure that compared to the honeycomb arrangement, the uniform arrangement can 325 hold less filaments, and the random arrangement can contain the maximum filaments among the 326 three cases. 


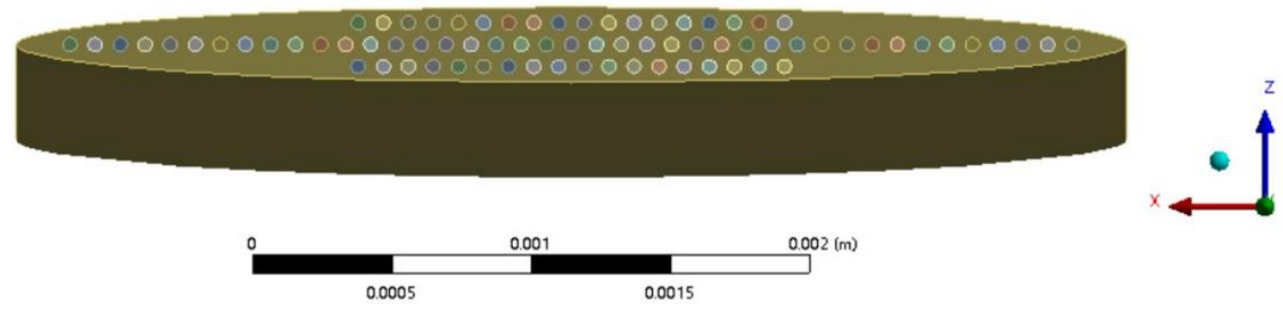

(a) Honeycomb arrangement
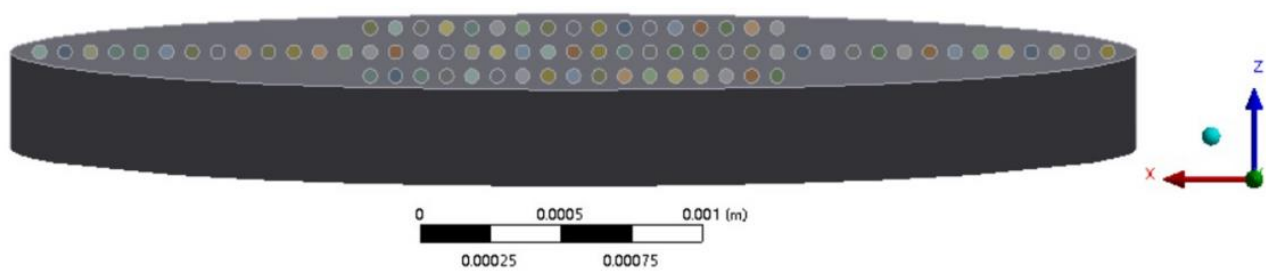

(b) Well pattern arrangement

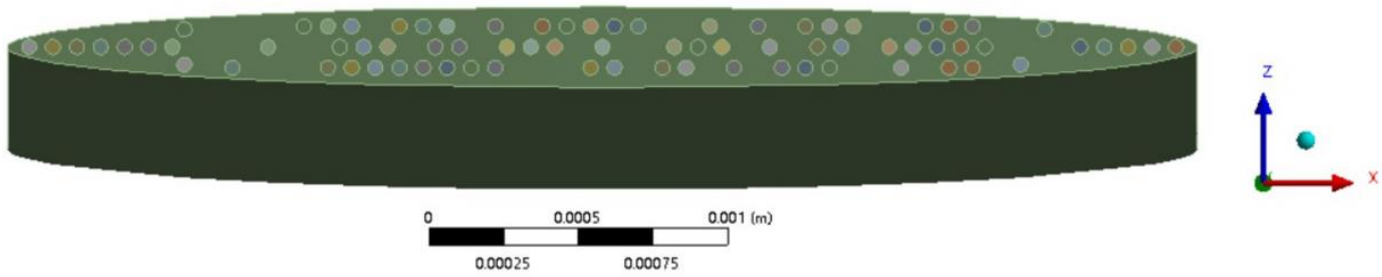

(c) Random arrangement

Fig. 13 Yarn diagram of filaments arranged in different ways.

The representative microscopic model of fiber cloth is loaded with uniaxial tensile load, and the stress-strain analysis is carried out. The elastic modulus is calculated according to the average stress and strain values of the representative elements under each fiber arrangement, as shown in Table 8. It can be found that the law of elastic modulus is similar to that of stress, and the higher the 338 randomness, the smaller the stress and elastic modulus. Consequently, it can be concluded that 339 when the fiber content remains constant, the honeycomb fiber composites can improve the bonding 340 interface between resin and fiber, the elastic modulus and friction properties of the materials, and 341 the load-bearing capacity. Therefore, in the second step, the representative volume unit of the 342 mesoscopic model of carbon fiber reinforced polymer (CFRP) and epoxy resin reinforced braided 
343 fiber cloth is modeled by using the honeycomb arrangement method. The macroscopic material 344 parameters of CFRP and epoxy resin reinforced braided fiber cloth are calculated by using the same 345 mechanical calculation method to transfer them from mesoscopic scale to macroscopic scale. In the 346 third step, the macroscopic plane is modeled through the software SpaceClaim. In the fourth step, 347 ANSYS ACP software is used to build the lay-up model for the macroscopic plane model. The 348 material parameters extracted from the macroscopic model are used as the lay-up material 349 parameters, and the lay-up effects from different angles are considered. Finally, the models are 350 combined.

Table 8. Representative unit indicators of different arrangements

\begin{tabular}{cccc}
\hline Arrangement mode & Average strain & Mean Mises stress (GPa) & Elastic modulus (MPa) \\
\hline Honeycomb & 0.693 & 19.25 & 0.432 \\
Well pattern & 0.711 & 18.21 & 0.315 \\
Random & 0.719 & 15.22 & 0.249 \\
\hline
\end{tabular}
average size.
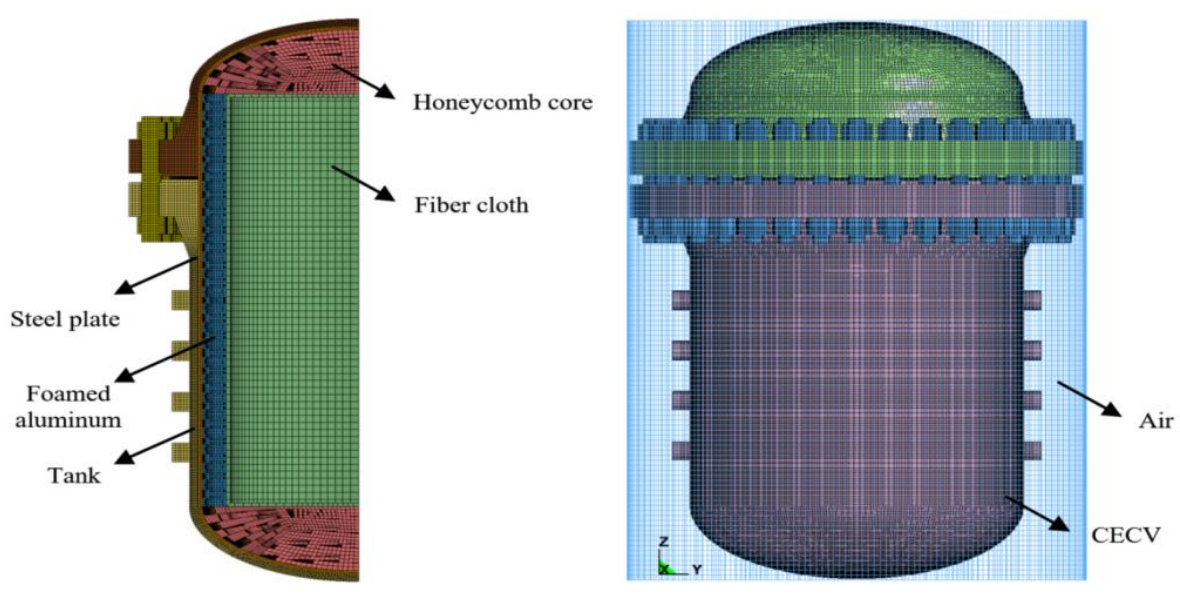
Fig. 14 FE model of the CECV. The specific parameters of each part of the CECV are shown in Table 9.

Table 9. Specific parameters of CECV

\begin{tabular}{cccc}
\hline $\begin{array}{c}\text { Fiber cloth } \\
\text { thickness }(\mathrm{mm})\end{array}$ & $\begin{array}{c}\text { Honeycomb core } \\
\text { thickness }(\mathrm{mm})\end{array}$ & $\begin{array}{c}\text { Thickness of lined } \\
\text { steel plate }(\mathrm{mm})\end{array}$ & $\begin{array}{c}\text { Thickness of honeycomb core } \\
\text { of end cover }(\mathrm{mm})\end{array}$ \\
\hline 10 & 60 & 10 & 189.95 \\
\hline
\end{tabular}

\subsection{Material model and contact algorithm of particles}

361 The fiber cloth is composed of epoxy resin reinforced braided carbon fibers and glass FRP

362 epoxy resin UD model, which are defined as Fabric 2 and Fabric 1, respectively. The laying order is

363 1-2-1-2-1. Five working conditions under fiber laying angles of $0^{\circ} / 0^{\circ} / 0^{\circ} / 0^{\circ} / 0^{\circ}, 0^{\circ} / 30^{\circ} / 60^{\circ} / 30^{\circ} /$

$3640^{\circ}$, and $0^{\circ} / 45^{\circ} / 90^{\circ} / 45^{\circ} / 0^{\circ}$ and explosive masses of $1.4,1.6,1.8$, and $3 \mathrm{~kg}$ are set. The material

365 parameters of carbon fiber epoxy resin UD model and FRP epoxy resin UD model obtained by 366 quasi-static tensile test are shown in Table 10 and 11.

Table 10. Material parameters of carbon fiber epoxy resin UD model

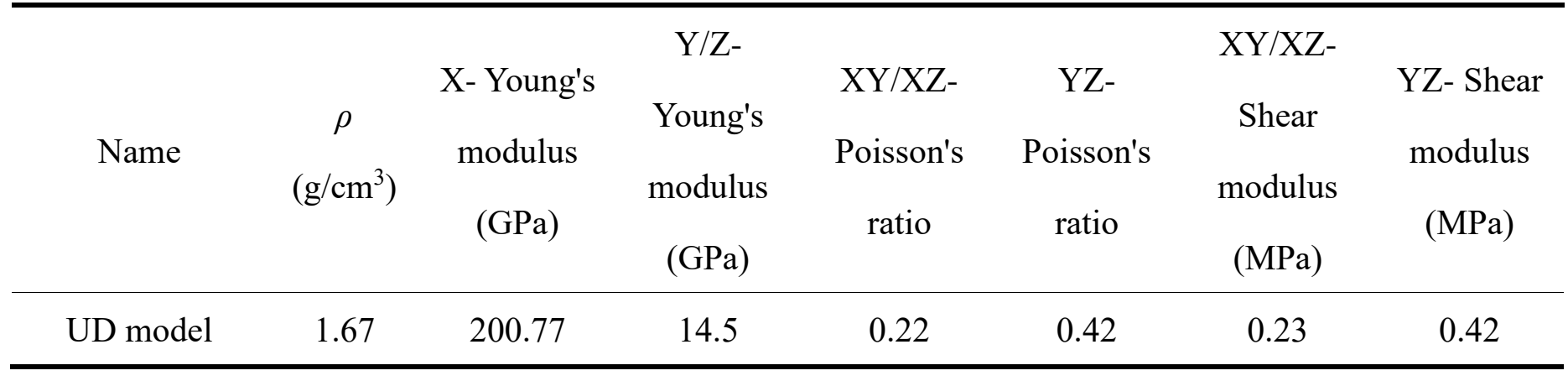

Table 11. Material parameters of FRP epoxy resin UD model

\begin{tabular}{cccccccc}
\hline & & & Y/Z- & & & XY/XZ- & \\
Name & $\rho$ & X- Young's & Young's & XY/XZ- & YZ- & Shear & YZ- Shear \\
& $\left(\mathrm{g} / \mathrm{cm}^{3}\right)$ & modulus & modulus & Poisson's & Poisson's & & modulus \\
& & $(\mathrm{GPa})$ & ratio & ratio & modulus & $(\mathrm{MPa})$ & \\
& & & & & & & \\
\hline
\end{tabular}


UD

model

2.0

45

10

0.3

0.4

5.0

3.846

The material parameters of carbon fiber epoxy resin braided fiber cloth are obtained by numerically simulating the quasi-static tensile test of the representative volume unit of its meso-model, as shown in Table 12.

Table 12. Material parameters of carbon fiber epoxy resin braided fiber cloth.

\begin{tabular}{ccccc}
\hline Name & $\rho\left(\mathrm{g} / \mathrm{cm}^{3}\right)$ & Elastic modulus $(\mathrm{GPa})$ & Shear modulus (GPa) & Poisson's ratio \\
\hline Weaving model & 1319.6 & 42.881 & 1.775 & 0.47595 \\
\hline
\end{tabular}

To accurately analyze the nonlinear behavior of aluminum honeycomb core under strong dynamic load, the PLASTIC KINEMATIC material model in LS-DYNA is used to describe its material properties. The matrix material of aluminum honeycomb core is aluminum alloy, and its composition is Al-Si (7-9\%)-Mg (0.5-1\%). The specific parameters are shown in Table 13.

Table 13. Material parameters of aluminum honeycomb core

\begin{tabular}{ccccc}
\hline$\rho\left(\mathrm{g} / \mathrm{cm}^{3}\right)$ & $E(\mathrm{GPa})$ & $v$ & $\operatorname{SIGY}(\mathrm{MPa})$ & $\operatorname{ETAN}(\mathrm{GPa})$ \\
\hline 2.73 & 70 & 0.34 & 185 & 4.62 \\
\hline
\end{tabular}
as 0.37 [32]. It may be noted that friction exists between the matrix material and fiber material in actual fiber composite components, and the measurement of friction coefficient is very difficult.

381 Therefore, to simplify the model and reduce the amount of calculation, in the macroscopic model of

382 fiber composite materials, the contact between matrix epoxy resin and fiber materials is set to 383 common node contact. The FE model of carbon fiber braided fabric and the UD model of FRP 
epoxy resin are divided by a hexahedron, and the mesh quality is high.

\subsection{Numerical results and discussion}

Fig. 15 shows the pressure-time history curve of multi-layer CECV and single-layer ECV at the measurement point P1 under $150 \mathrm{~g}$ TNT equivalent. Through comparison, it is clear that the steel plate-aluminum honeycomb-fiber cloth protective structure can prolong the action time of performance of CECV is significantly enhanced.

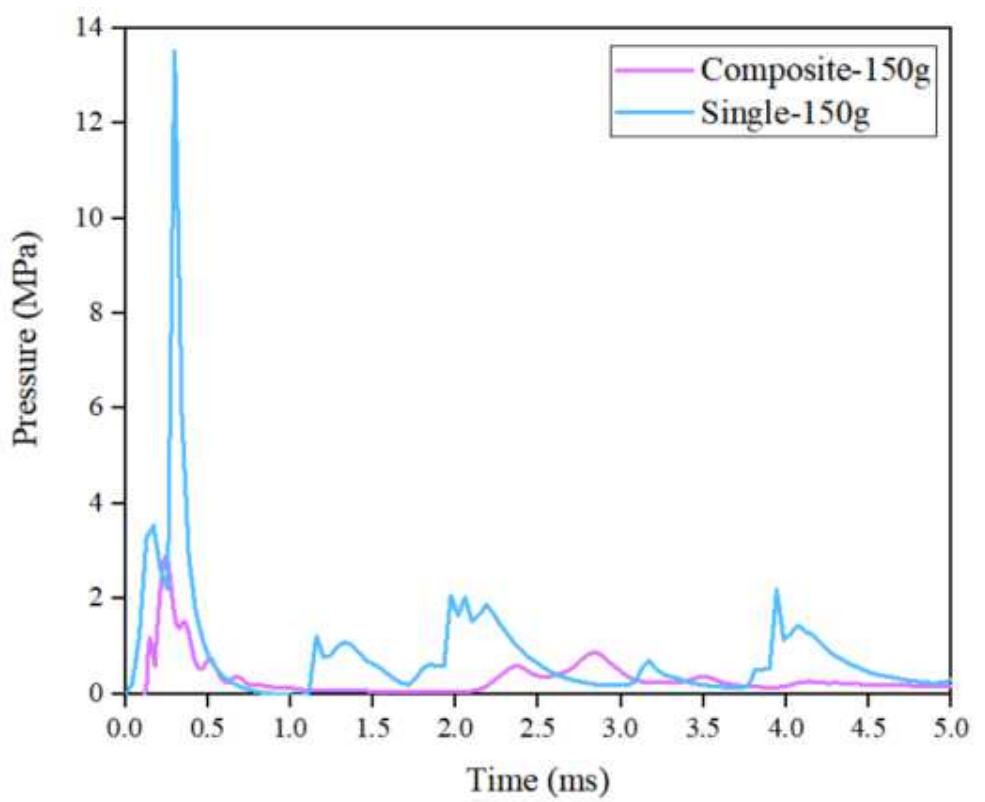

Fig. 15 Peak overpressure-time curves of multi-layer CECV and single-layer ECV at the end cap.

Fig. 16 shows the pressure-time history curve of each measurement point of the CECV under

$1.2 \mathrm{~kg}$ and $1.6 \mathrm{~kg}$ explosives for different fiber laying angles. The peak reflection overpressure of each measurement point decreases with the increase in the proportional blasting distance, and the peak pressure is the highest at the measurement point P5, and the load at the end cover is the largest, which is still the weakest position of the explosion tank. The pressure-time history curves of each measurement point under different laying angles of fiber cloth are basically similar, which indicates 
399 that the laying angle of fiber cloth has no effect on the peak overpressure in the explosion tank.

400 Furthermore, it is clear from Figs. 16(a) and (b) that as the weight of explosive increases, the 401 pressure of each measurement point in the explosion tank increases.

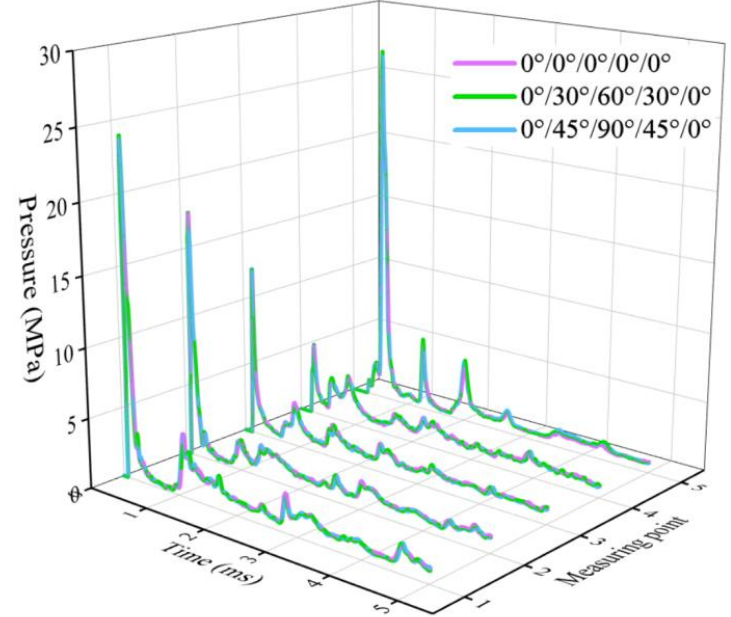

(a) $1.2 \mathrm{~kg}$

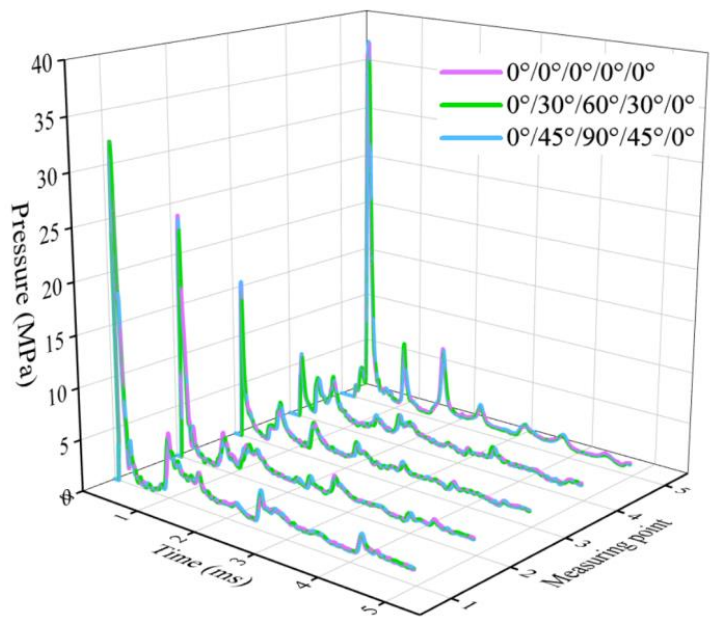

(b) $1.6 \mathrm{~kg}$
402

403

404

405

406

407

408

409

Fig. 16 Pressure-time curves inside the explosion tank.

Figs. 17 and 18 show the stress-time curves and peak stress values, respectively, of the CECV at each measurement point under different fiber laying angles for the explosive mass of 1.2, 1.4, 1.6, 1.8 , and $3 \mathrm{~kg}$. When the explosive mass is $3 \mathrm{~kg}$ and the fiber laying angle is $0^{\circ} / 0^{\circ} / 0^{\circ} / 0^{\circ} / 0^{\circ}$, the composite tank is destroyed, so the corresponding stress value is not shown. It can be seen from the figure that the peak stress of each measurement point gradually decreases with the increase in the proportional blasting distance under the three laying angles. The peak stress under $1.2 \mathrm{~kg}$ explosive shows a linearly decreasing trend, and the maximum stress is obtained at the end cover. Further, under the three fiber laying angles, the stress of the composite tank increases with the increase in the amount of explosive. The peak stress value of each measurement point under different explosive quantities and fiber laying angles is summarized in Fig. 18. It can be found that under different 
413 explosive quantities, for the fiber composite plate with single-direction laying angle, the increase of 414 laying angle has no obvious effect on the vibration isolation performance of the CECV. The peak 415 stress value of the CECV for fiber laying angle of $0 \% 45^{\circ} / 90^{\circ} / 45^{\circ}$ o is less than that for the other 416 two fiber laying angles. This indicates that the best protective effect of CECV is obtained when the 417 laying angle of the fiber cloth is $0^{\circ} / 45^{\circ} / 90^{\circ} / 45^{\circ} / 0^{\circ}$.

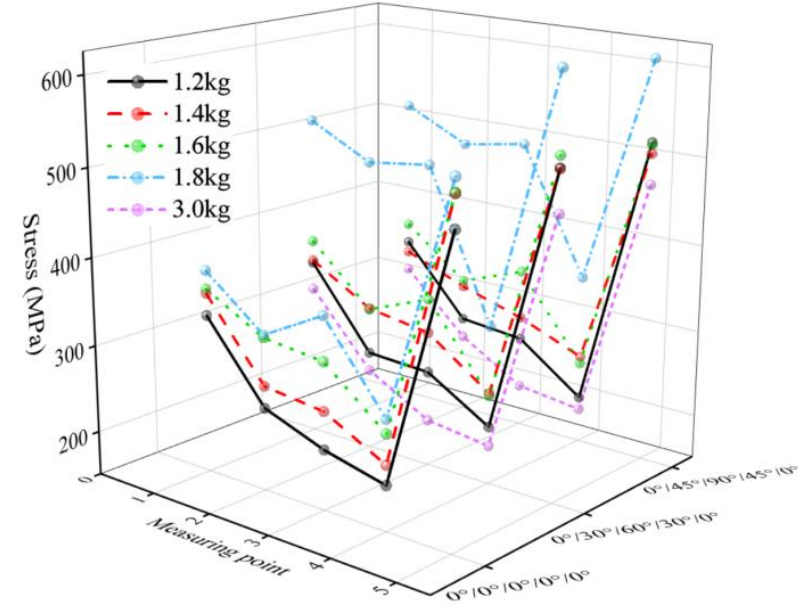

Fig. 17 Stress-time curves.

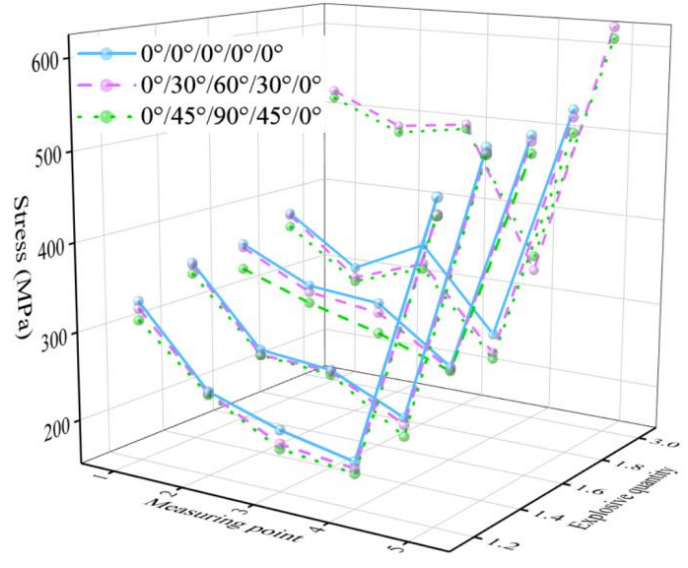

Fig. 18 Peak stress of CECV.

Table 14. Summary of peak stress of CECV

\begin{tabular}{|c|c|c|c|c|c|c|}
\hline \multirow{2}{*}{$\begin{array}{c}\text { Explosive } \\
\text { quantity (kg) }\end{array}$} & \multirow{2}{*}{ Laying angle } & \multicolumn{5}{|c|}{ Measurement point } \\
\hline & & P1 & $\mathrm{P} 2$ & P3 & P4 & P5 \\
\hline \multirow{3}{*}{1.2} & $0^{\circ} / 0^{\circ} / 0^{\circ} / 0^{\circ} / 0^{\circ}$ & 332.00 & 244.88 & 218.52 & 201.37 & 488.89 \\
\hline & $0^{\circ} / 30^{\circ} / 60^{\circ} / 30^{\circ} / 0^{\circ}$ & 323.76 & 243.00 & 203.00 & 194.00 & 471.00 \\
\hline & $0^{\circ} / 45^{\circ} / 90^{\circ} / 45^{\circ} / 0^{\circ}$ & 310.41 & 241.23 & 197.71 & 188.67 & 470.55 \\
\hline \multirow{3}{*}{1.4} & $0^{\circ} / 0^{\circ} / 0^{\circ} / 0^{\circ} / 0^{\circ}$ & 357.28 & 269.79 & 261.66 & 223.86 & 525.00 \\
\hline & $0^{\circ} / 30^{\circ} / 60^{\circ} / 30^{\circ} / 0^{\circ}$ & 355.00 & 264.00 & 260.00 & 216.00 & 519.37 \\
\hline & $0^{\circ} / 45^{\circ} / 90^{\circ} / 45^{\circ} / 0^{\circ}$ & 344.65 & 263.59 & 256.54 & 203.06 & 517.82 \\
\hline
\end{tabular}




\begin{tabular}{|c|c|c|c|c|c|c|}
\hline \multirow{3}{*}{1.6} & $0^{\circ} / 0^{\circ} / 0^{\circ} / 0^{\circ} / 0^{\circ}$ & 362.29 & 324.59 & 316.97 & 258.04 & 525.20 \\
\hline & $0^{\circ} / 30^{\circ} / 60^{\circ} / 30^{\circ} / 0^{\circ}$ & 358.00 & 317.00 & 306.00 & 255.00 & 519.00 \\
\hline & $0^{\circ} / 45^{\circ} / 90^{\circ} / 45^{\circ} / 0^{\circ}$ & 332.23 & 304.14 & 282.35 & 253.04 & 505.57 \\
\hline \multirow{3}{*}{1.8} & $0^{\circ} / 0^{\circ} / 0^{\circ} / 0^{\circ} / 0^{\circ}$ & 383.24 & 327.84 & 367.17 & 273.97 & 541.29 \\
\hline & $0^{\circ} / 30^{\circ} / 60^{\circ} / 30^{\circ} / 0^{\circ}$ & 381.00 & 316.00 & 345.00 & 252.00 & 533.00 \\
\hline & $0^{\circ} / 45^{\circ} / 90^{\circ} / 45^{\circ} / 0^{\circ}$ & 366.98 & 311.37 & 339.03 & 245.04 & 515.62 \\
\hline \multirow{2}{*}{3} & $0^{\circ} / 30^{\circ} / 60^{\circ} / 30^{\circ} / 0^{\circ}$ & 522.79 & 486.92 & 496.95 & 331.46 & 623.56 \\
\hline & $0^{\circ} / 45^{\circ} / 90^{\circ} / 45^{\circ} / 0^{\circ}$ & 514.03 & 479.20 & 491.69 & 348.33 & 610.52 \\
\hline
\end{tabular}

420 show the peak stress of steel plate and aluminum honeycomb core at different fiber laying angles

421 under $1.2,1.4,1.6,1.8$, and $3 \mathrm{~kg}$ explosives. It is clear that the peak stress of each measurement

422 point of the composite tank gradually decreases with the increase in the proportional blasting

423 distance under the three laying angles, and the five measurement points (P1-P5) exhibit the

424 maximum stress, i.e., the stress of the steel plate and aluminum honeycomb core is highest at the

425 end cover. Further, under the three fiber laying angles, the stress of steel plate and aluminum

426 honeycomb core increases with the increase in explosive amount, but the increase of aluminum

427 honeycomb core is larger than that of steel plate. According to Figs. 19 and 20, it can be inferred

428 that under different explosive quantities, for the fiber composite plate with laying angle of $0 \% 0 \%$

$4290^{\circ} / 0^{\circ} / 0^{\circ}$, the increase of laying angle $\left(0^{\circ} / 30^{\circ} / 60^{\circ} / 30^{\circ} / 0^{\circ}\right)$ has no obvious effect on the explosion

430 resistance of protective materials (steel plate and aluminum honeycomb core) of composite tank.

431 The peak stress value of the steel plate and aluminum honeycomb core for the fiber laying angle of 
433 protective effect of the explosion tank is the best when the laying angle of the fiber cloth is $0^{\circ} / 45^{\circ}$

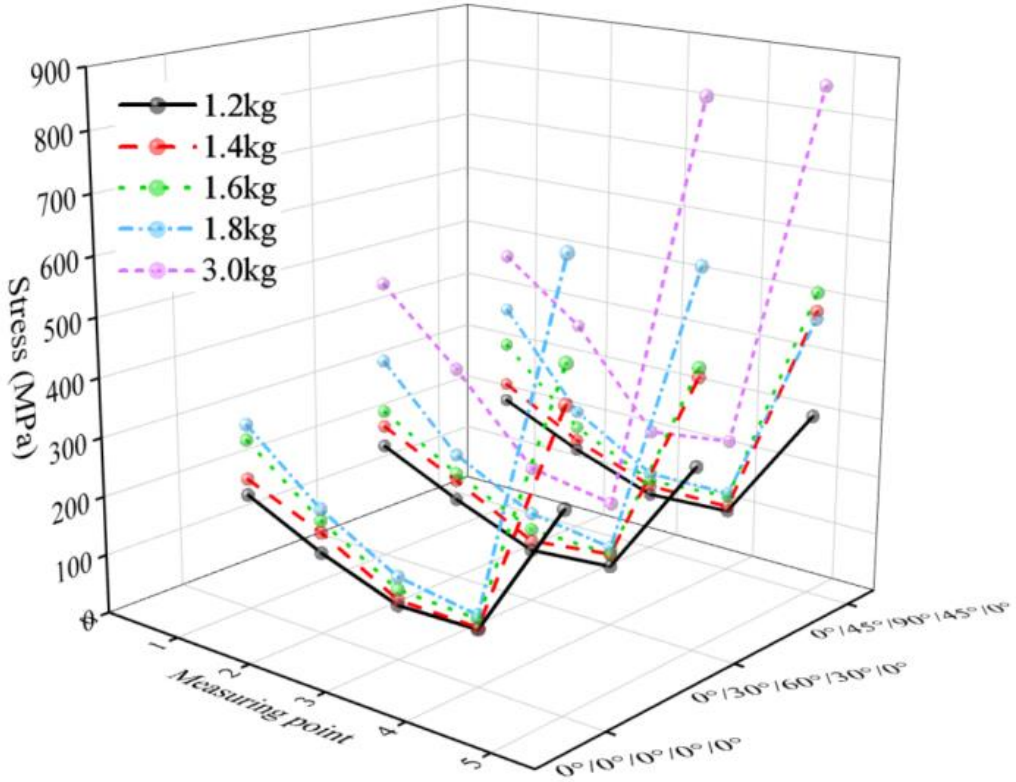

Fig. 19 Peak stress of steel plate

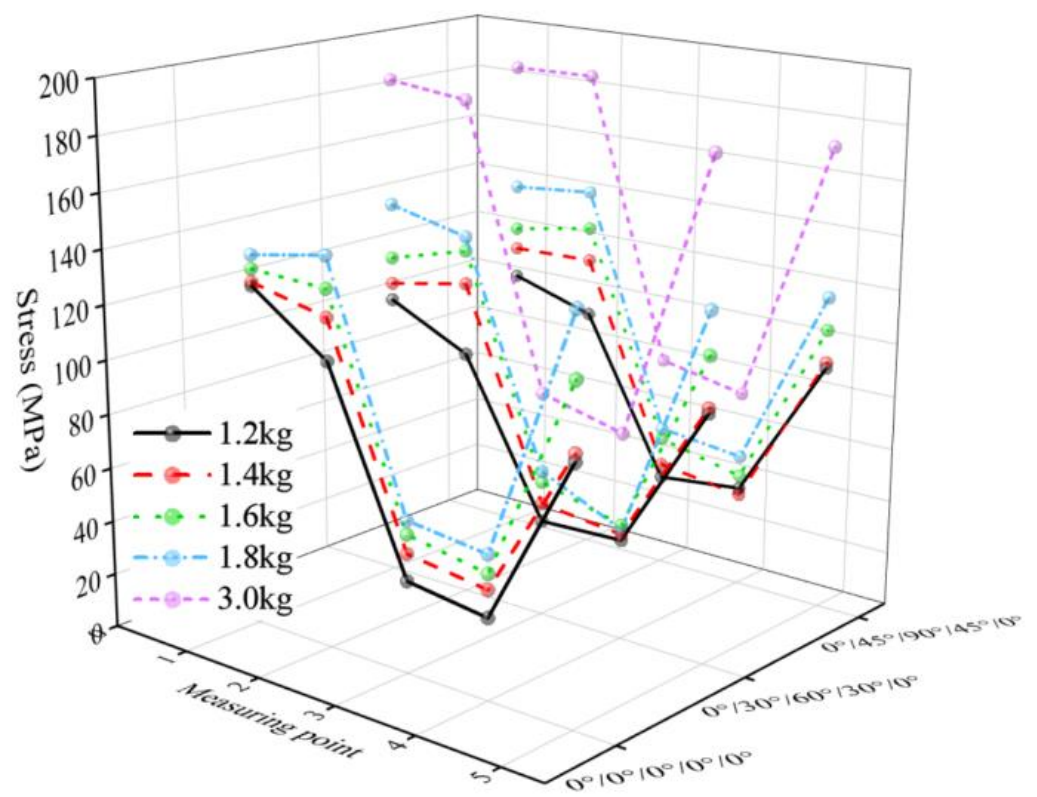

Fig. 20 Peak stress of aluminum honeycomb core 
ECV. It is clear that the protective layer of the composite tank can greatly reduce the circumferential strain of the explosion tank. After adding the protective structure of steel plate-aluminum 443 honeycomb-fiber cloth, the strain is reduced and the beat effect of the explosion tank is avoided, 444 while the strain of the shell of the single-layer explosion tank shows a consistent periodic 445 fluctuation characteristic due to the beat effect, which continuously oscillates in the time duration of $4465 \mathrm{~ms}$. It shows that the inner lining design can significantly improve the anti-explosion and 447 wave-absorption ability of the ECV.

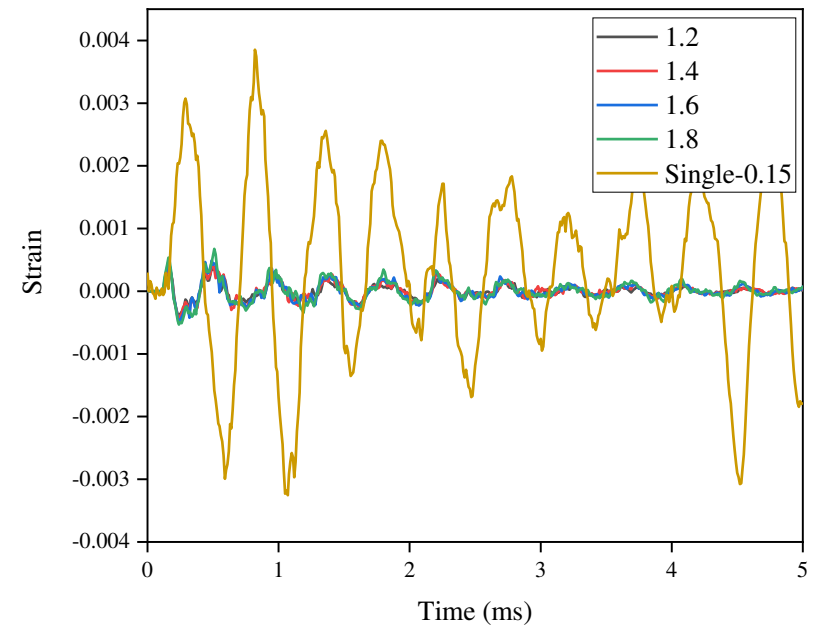

(a) $0 \% 0^{\circ} / 0^{\circ} / 0^{\circ} / 0^{\circ}$

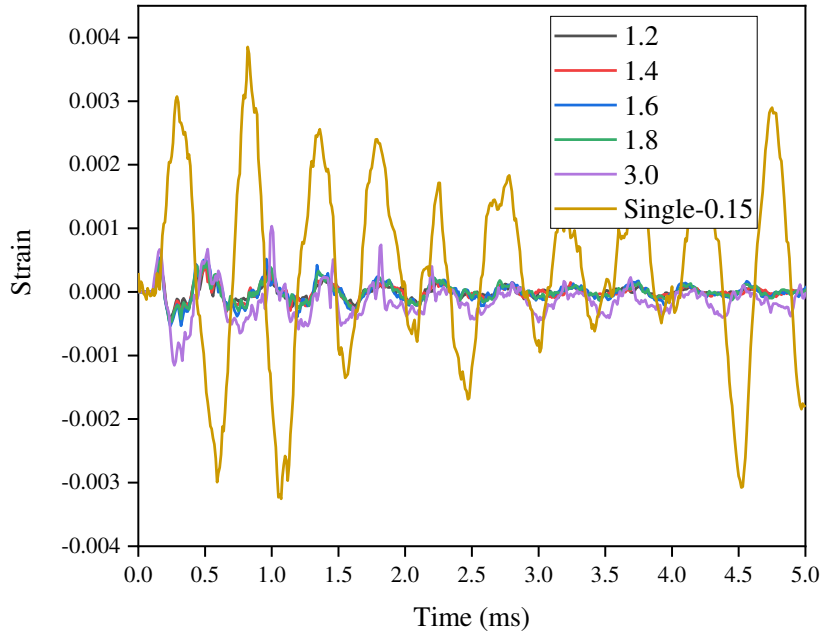

(b) $0^{\circ} / 30^{\circ} / 60^{\circ} / 30^{\circ} / 0^{\circ}$

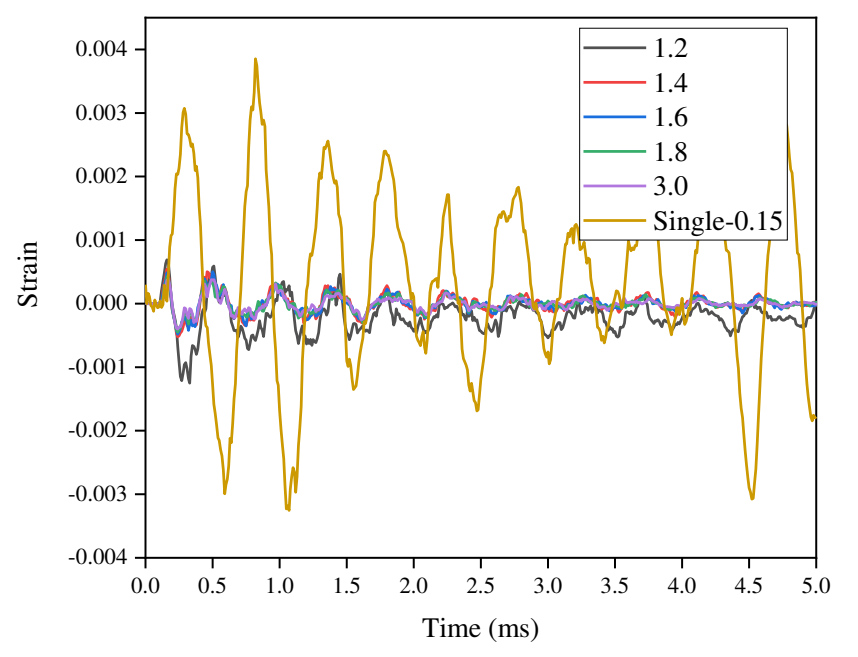

(c) $0^{\circ} / 45^{\circ} / 90^{\circ} / 45^{\circ} / 0^{\circ}$

Fig. 21 Strain-time history curves of the measurement point P1 


\section{Conclusion}

In this paper, the internal explosion pressure load of a single-layer ECV was examined through experiments and numerical simulations. Then, the load characteristics were analyzed, and the weakest position of the ECV was determined, based on which a multi-layer CECV was designed.

The random distribution and uniform distribution characteristics of fiber filaments in the yarn were studied at the micro scale, and uniform distribution, random distribution, and honeycomb distribution algorithms were proposed for the fiber well pattern based on Python language. Furthermore, a 3D meso-model of the multi-layer CECV was established, and the internal load

461 distribution of the explosion tank and the stress of the protective structure were analyzed. The main 462 results of the study are summarized as follows:

(1) When the fiber content remained constant, compared with the uniform arrangement and 464 random arrangement of fiber filaments, the fiber composites with honeycomb arrangement of fiber 465 filaments improved the bonding interface between resin and fibers as well as the elastic modulus 466 and friction properties of the materials and exhibited higher load-bearing capacity.

(2) The simulation results of the single-layer ECV were in good agreement with the 468 experimental results, which verified the accuracy of the 3D numerical model. The 3D model could 469 predict the propagation of the shock waves in the single-layer ECV, and the end cover was 470 determined as the weakest position.

(3) A sliding steel plate-aluminum honeycomb-fiber cloth protective structure was used to

472 design the multi-layer $\mathrm{CECV}$, and the corresponding meso-model was established. Under the action 473 of explosion, the protective structure of steel plate-aluminum honeycomb-fiber cloth prolonged the 
474 action time of explosion shock wave and reduced the peak pressure in the explosion tank, and the 475 laying angle of fiber cloth did not affect the peak overpressure inside the explosion tank. The best 476 protective effect was obtained when the laying angle of fiber cloth was $0^{\circ} / 45^{\circ} / 90^{\circ} / 45^{\circ} / 0^{\circ}$.

477 (4) The protective structure of steel plate-aluminum honeycomb-fiber cloth enhanced the 478 anti-explosion ability of the CECV. Consequently, the strain value of P1 measurement point of 479 composite tank under $3 \mathrm{~kg}$ TNT was less than that of single-layer tank under $150 \mathrm{~g}$ TNT.

480 Conflicts of Interest

$481 \quad$ The authors declare no conflict of interest.

482 Acknowledgement

483 This study was supported by the Young Scientists Fund of the National Natural Science 484 Foundation of China (Grant No. 11902157) and the Basic research Program of Jiangsu Province 485 (Natural Science Foundation, Grant No. BK20180417).

\section{Data availability statements}

The data used to support the findings of this study have been deposited in the "figshare" 488 repository (Yuan Qi, Chen Heng, Gu Wenbin, Wang Zhen, Hao Likai (2021): data.zip. figshare. 489 Dataset. https://doi.org/10.6084/m9.figshare.16419627.v1), and the data used to support the 490 findings of this study are included within the article. 


\section{Reference}

493 [1] Chen YJ, Wu XD, Zheng JY, Deng GD, Li QM. Dynamic responses of discrete multi-layered 494 explosion containment vessels with the consideration of strain-hardening and strain-rate effects. 495 Int J Impact Eng 2010, 37(7):842-853.

496 [2] Ma L, Xin J, Hu Y, Zheng J. Ductile and brittle failure assessment of containment vessels subjected to internal blast loading. Int J Impact Eng 2013, 52: 28-36.

498 [3] Dong Q, Li QM, Zheng JY. Further study on strain growth in spherical containment vessels subjected to internal blast loading. Int J Impact Eng 2010, 37(2): 196-206.

[4] Clayton AM. A simplified method to determine initial estimates of peak strains in composite explosive containment vessels. // Asme Pressure Vessels \& Piping Conference. 2013.

[5] Ren XJ, Li GG, Zhang SG. Experimental study on explosion resistance of aluminum foam sandwich explosion tank. Shock Vib 2011, 30 (5): 213-17.

[6] L. Wang, Study on load law and dynamic response of composite explosion-proof vessel. Zhejiang University, 2012.

[7] Cui YX, Hu YL, Wang CM, Hu H, Chen PW. Dynamic response of multi-layer steel cylinder under internal intense blast loading. Explosion and Shock Waves 2015, 35(6): 820-824.

[8] Dong Q, Hu B. Dynamic behavior of carbon fiber explosion containment vessels. J. Press. Vessel Technol. 2016, 138(1).

510 [9] Liu X, Gu WB, Liu JQ, Xu JL, Hu YH, Hang YM. Dynamic response of cylindrical explosion containment vessels subjected to internal blast loading. Int J Impact Eng 2020, 135: 103389.

512 [10]Baker WE. The elastic-plastic response of thin spherical shells to internal blast loading. J Appl 

Mech 1960;27(1):139-44.

514 [11]Duffey TA, Mitcheli D. Containment of explosions in cylindrical shells. Int J Mech Sci $1973 ; 15(3): 237-49$.

[12]Zhu W H, Xue H L, Zhou G Q, G.K. Schleyer. Dynamic response of cylindrical explosive chambers to internal blast loading produced by a concentrated charge. International Journal of Impact Engineering, 1997, 19(9-10): 831-845.

[13] Wang X, Gong YN. An elastodynamic solution for multilayered cylinders. Int J Eng Sci 1992, 30(1):25-33.

[14]Zheng JY, Chen YJ, Deng GD, Sun GY, Hu YL, Li QM. Dynamic elastic response of an infinite discrete multi-layered cylindrical shell subjected to uniformly distributed pressure pulse. Int $\mathbf{J}$ Impact Eng 2006, 32(11):1800-27. Press. Vessel Technol. 2019, 141(4).

[16]Karpp R R, Duffey T A, Neal T R. Response of containment vessels to explosive blast loading. $1983,105: 23-27$

[17]T.A. Duffey, R. Martineau, R.R. Stevens, C. Romero, Vessel closure bolt response under impulsive loading. American Society of Mechanical Engineers 2000, (399):95-98.

[18] Duffey T, Mitchell D. Containment of explosions in cylindrical shells. Int. J. Mech. Sci 1973, 15(3):237-249.

[19]Dong Q, Li Q M, Zheng J. Strain growth in a finite-length cylindrical shell under internal pressure pulse. J Press. Vessel Tech 2017, 139(2). 
534 [20]Dong Q, Li Q M, Zheng J Y. Guidelines for the design of multiple-use explosion containment 535 vessels based on the understanding of the strain growth phenomenon. J. Perform. Constr. Facil $536 \quad 2011,25(5): 394-399$.

537 [21]G. Deng. Research on internal explosive loadings and blast resistant characteristics of discrete 538 multi-layered explosion containment vessels. Zhejiang University, 2008.

539 [22]J.D. Lin. Chemical explosion loads in enclosed space and wave attenuation of sand wall. 540 Journal of PLA University of Science and Technology (Natural Science Edition) 2007, $541 \quad(8): 559-566$.

542 [23]H.O. Zhao. LS-DYNA Dynamic Analysis Guide. Ordnance Industry Press: Beijing, China, 5432003.

544 [24]Zhang CY, Tang LQ, Yang B, Zhang L, Huang XQ, Fang DN. Meso-mechanical study of 545 collapse and fracture behaviors of closed-cell metallic foams. Comput. Mater. Sci 2013, $546 \quad(79): 45-51$.

547 [25] Langdon, GS, Ozinsky A, Yuen SCK. The response of partially confined right circular stainless steel cylinders to internal air-blast loading. Int. J. Impact Eng 2014, (73):1-14.

549 [26]Langdon GS, Rossiter IB, Balden VH, Nurick GN. Performance of mild steel perforated plates 550 as a blast wave mitigation technique. Int. J. Impact Eng 2010, (37):1021-1036.

551 [27]Jacob N, Nurick GN, Langdon GS. The effect of stand-off distance on the failure of fully clamped circular mild steel plates subjected to blast loads. Eng Struct 2007, (29):2723-2736.

553 [28]Hong X, Li W, Cheng W, Li W B, Xu H Y. Numerical simulation of the blast wave of a 554 multilayer composite charge. Defence Technology, 2020, 16(1): 96-106. 
555 [29]X.R. Liu, X.G. Tian, T.J. Lu, B. Liang. Sandwich plates with functionally graded metallic foam 556 cores subjected to air blast loading. Int. J. Mech. Sci 2014, (84):61-72.

557 [30]Liu X, Tian X, Lu TJ, Zhou D, Liang B. Blast resistance of sandwich-walled hollow cylinders $558 \quad$ with graded metallic foam cores. Compos. Struct 2012, (94) 2485-93.

559 [31]Xiong J, Feng L, Ghosh R, Wu H, Wu L, Ma L, Vaziri A. Fabrication and mechanical behavior 560 of carbon fiber composite sandwich cylindrical shells with corrugated cores. Compos. Struct $561 \quad 2016,(156): 307-319$.

562 [32] Song HW, He QJ, Xie JJ, Tobota A. Fracture mechanisms and size effects of brittle metallic 563 foams: In situ compression tests inside SEM. Compos. Sci. Tech 2008, (68) 2441-50. 